\title{
Speech-specific perceptual adaptation deficits in children and adults with dyslexia
}

Ola Ozernov-Palchik ${ }^{1,2, *}$, Sara D. Beach ${ }^{1,3}$, Meredith Brown ${ }^{4}$, Tracy M. Centanni ${ }^{5}$, Nadine Gaab ${ }^{2}$, Gina Kuperberg $^{4}$, Tyler K. Perrachione ${ }^{6}$, John D. E. Gabrieli ${ }^{1,3}$

1 McGovern Institute for Brain Research, Massachusetts Institute of Technology, Cambridge, Massachusetts, USA

2 Harvard Graduate School of Education, Harvard University, Cambridge, Massachusetts, USA

3 Program in Speech and Hearing Bioscience and Technology, Harvard Medical School, Boston, MA, USA

4 Department of Psychology, Tufts University, Medford, Massachusetts, USA

5 Department of Psychology, Texas Christian University, Fort Worth, Texas, USA

6 Department of Speech, Language, and Hearing Sciences, Boston University, Boston, MA, USA

* Correspondence to: Ola Ozernov-Palchik, PhD., McGovern Institute, MIT, 77 Massachusetts Avenue Cambridge, MA 02139,

Email: oozernov@mit.edu.

\section{Data and Code Availability}

The data and the analysis code used to support the findings of this study have been deposited in a Github repository (https://github.com/oozernov/speech_specific_deficit_paper)

\section{Funding}

This research was supported by the Halis Foundation for Dyslexia Research at MIT (to JDEG) and the National Institutes of Health (F32-HD100064 to OO; R01-HD067312 to JDEG and NG; F31-HD100101 to SDB).

\section{Notes}

We thank our participants. We thank Kelly Halverson, Sidney May, and Karolina Wade for their assistance in collecting and scoring the behavioral data. Conflict of Interest: None declared 


\begin{abstract}
According to several influential theoretical frameworks, phonological deficits in dyslexia result from reduced sensitivity to acoustic cues that are essential for the development of robust phonemic representations. Some accounts suggest that these deficits arise from impairments in rapid auditory adaptation processes that are either speech-specific or domain-general. Here, we examined the specificity of auditory adaptation deficits in dyslexia using a non-linguistic tone anchoring (adaptation) task and a linguistic selective adaptation task in children and adults with and without dyslexia. Children and adults with dyslexia had elevated tone-frequency discrimination thresholds, but both groups benefitted from anchoring to repeated stimuli to the same extent as typical readers. Additionally, although both dyslexia groups had overall reduced accuracy for speech sound identification, only the child group had reduced categorical perception for speech. Across both age groups, individuals with dyslexia had reduced perceptual adaptation to speech. These results highlight broad auditory perceptual deficits across development in individuals with dyslexia for both linguistic and non-linguistic domains, but speech-specific adaptation deficits. Finally, mediation models in children and adults revealed that the causal pathways from basic perception and adaptation to phonological awareness through speech categorization were not significant. Thus, rather than having causal effects, perceptual deficits may co-occur with the phonological deficits in dyslexia across development.
\end{abstract}

Keywords: auditory processing, perceptual adaptation, dyslexia, development, tonefrequency discrimination, categorical perception 


\section{Speech-Specific Perceptual Adaptation Deficits in Children and Adults with Dyslexia}

Developmental dyslexia is a neurobiological disorder defined by atypical reading development. The phonological theory of dyslexia suggests that children with dyslexia struggle to learn to read due to difficulties with storing, retrieving, and/or manipulating phonological representations (Brady et al., 1983; Shankweiler et al., 1979; Snowling, 2000; Stanovich \& Siegel, 1994; Vellutino et al., 1994). Phonological difficulty impairs the mapping of speech sounds to letters and subsequently affects accurate and fluent reading. A key question is whether phonological deficits are a consequence of broader underlying auditory perceptual impairments (Ahissar et al., 2006; Goswami, 2011; Tallal, 1980).

There is evidence for broader auditory processing deficits in dyslexia that could be responsible for poor phonological processing in dyslexia, including discrimination of pitch and frequency modulation in quiet and in noise (Ahissar et al., 2000; Amitay et al., 2002; Lorusso et al., 2014; Wright et al., 2011; Ziegler et al., 2009) and in slow (Goswami, 2002) as well as fast (Tallal \& Piercy, 1973) temporal transitions. Tone-frequency discrimination is one of the most frequently studied aspects of auditory processing in dyslexia (reviewed in Hämäläinen et al., 2013), and individuals with dyslexia consistently show elevated discrimination thresholds (reviewed in Witton et al., 2020). Causal models of dyslexia propose that impaired processing of acoustic frequency impedes the use of phonetic information during speech processing, resulting in "fuzzier" phonemic representations, and subsequently, in atypical phonological development (Goswami, 2011; Tallal et al., 1993). Evidence for these causal pathways, however, is limited and inconsistent (Hämäläinen et al., 2013; Poelmans et al., 2011; Vanvooren et al., 2017). 
An alternative idea is that dyslexia is not characterized by a fundamental weakness in auditory perception but rather by a weakness in adaptation to, or rapid learning about, featural consistency in auditory stimuli (Ahissar et al., 2006). Because the acoustic realization of phonemes varies across contexts (e.g., across speakers and words), generalization across different instances of the same phoneme is required (Pierrehumbert, 2003). Specifically, the acquisition of phonetic categories relies on the capacity to learn from and adapt to probabilistic information in the speech signal. These categories then become represented in the perceptual system as probability distributions over a multidimensional acoustic and articulatory space (Clayards et al., 2008). Categorical perception is the extent of segregation among the various phonetic distributions. Since there are extensive variations across speakers and linguistic contexts, to comprehend speech successfully, listeners depend on probabilistic acoustic-phonetic evidence and adapt their distributions accordingly to make judgments about the intended phonetic categories. Language unfolds rapidly, and therefore listeners experience rapid and ongoing adjustments to how speech acoustics are mapped to their phoneme representations - i.e., perceptual adaptation - as part of successful speech perception (Eisner \& Mcqueen, 2005; Eisner \& McQueen, 2006; Kraljic \& Samuel, 2006, 2007).

Diminished categorical perception of speech continua in individuals with dyslexia has been well documented (Noordenbos \& Serniclaes, 2015), although it has been also proposed that these deficits are stimulus dependent (e.g., Blomert et al., 2004). It remains unresolved why individuals with dyslexia show less categorical perception. It is possible that individuals with dyslexia have a reduced capacity for rapidly adapting to speech cues in order to identify and discriminate between phonemes, resulting in underspecified phonological representations. Indeed, there is evidence for both general auditory and speech-specific adaptation deficits in individuals with dyslexia (Ahissar 
et al., 2006; Amitay et al., 2002; Gabay et al., 2015, 2019; Gabay \& Holt, 2015, 2021; Perrachione et al., 2016).

Early evidence of an adaptation deficit came from a study in which participants had to indicate which of two sequential tones had a higher pitch (Ahissar et al., 2006). In the non-standard condition, the frequencies of both tones varied across trials, and in the standard condition, the frequency of one tone was held constant across trials. There were no differences in perceptual threshold between groups during the non-standard condition, suggesting no dyslexia-related deficits in frequency discrimination. Children with dyslexia, however, did not demonstrate the typical improvement in performance in the standard condition. This failure to benefit from stimulus regularity suggested that deficits observed in dyslexia stem from a reduced capacity for forming perceptual "anchors" (Ahissar et al., 2006; Ben-Yehudah \& Ahissar, 2004; Oganian \& Ahissar, 2012). The anchoring-deficit hypothesis thus proposes that the underlying deficits in dyslexia are not related to a weakness in auditory perceptual processing per se, but rather to a reduced capacity for rapidly adapting perceptual representations (including both linguistic and non-linguistic, and in auditory and non-auditory domains; Ahissar, 2007).

The findings of typical perceptual thresholds but attenuated adaptation in individuals with dyslexia suggest that the magnitude of adaptation effects is partially independent of the perceptual precision in processing the adaptive stimuli. According to speech perception models, adaptation behavior relies on both the underlying phonetic representations and the ability to update these representations given new information (Kleinschmidt \& Jaeger, 2015). Listeners have prior probabilistic beliefs about which distributions of acoustic cues represent a particular phonetic category, but these distributions shift as new contextual cues are integrated. Models of phonetic categorization often consider differences across speakers (e.g., accents) and environmental 
contexts (e.g., background noise) as factors affecting the extent to which prior beliefs are updated, driving subsequent changes in categorization behavior (Allen et al., 2003; Clayards et al., 2008; Kleinschmidt \& Jaeger, 2015; Kronrod et al., 2012; Newman et al., 2001). There is limited evidence, however, on whether and how within-listener factors, such as noisiness in the perceptual system, could affect the magnitude of change in behavior (Clayards et al., 2008; Feldman et al., 2009; Kronrod et al., 2012). Such sensory uncertainty could lead to a failure to identify repeated cues as consistent, and subsequently lead to attenuated adaptation. Less consistent phonetic categorization in individuals with dyslexia could also suggest a wider distributional space for how each phonetic category is represented. Alternatively, as in the tone anchoring finding, attenuated adaptation processes may be independent from sensory or representational uncertainty. Comparing perceptual acuity across linguistic and non-linguistic stimuli in relation to adaptation effects could help determine how listener-specific factors are related to adaptation, and whether the ability to rapidly adapt spans nonverbal and verbal audition.

Adaptation processes in speech have long been studied with a paradigm known as selective adaptation (Eimas \& Corbit, 1973a; Samuel, 1986). In these experiments, participants change the way they categorize items from a speech-sound continuum after repeated exposure to one of its endpoints. Specifically, after multiple exposures to a prototypical exemplar of /ba/, participants are less likely to classify a more ambiguous /ba/, from a more central point on the continuum, as /ba/. This results in fewer overall $/ \mathrm{ba} /$ classifications post-exposure to the $/ \mathrm{ba} /$ exemplar, and the shift of the categorical boundary toward the /ba/ endpoint, as compared to post-exposure to the /da/ exemplar or to a pre-adaptation baseline. The ability to perceive the adaptor as a repeating exemplar of a phonetic category is critical for adaptation to occur. Since this paradigm evaluates both categorical perception and perceptual adaptation in the speech domain, it could be used to 
dissociate categorical perception deficits in dyslexia from an underlying perceptual adaptation impairment. Finally, comparing the adaptation effects for speech and for tones could help determine whether adaptation deficits seen for linguistic stimuli are due to dysfunction of language-specific or audition-general mechanisms for adaptation.

Despite the potential of the selective adaptation paradigm to dissociate perceptual and adaptation deficits in dyslexia, only one study to date has applied the paradigm to this population. A study in 5-year-old Chinese children with dyslexia revealed both less sharp categorical boundaries and attenuated adaptation effects as compared to typically-reading age-matched children and adults (Liu et al., 2009). There were also developmental differences in the adaptation effect, with a significantly more robust adaptation effect in typical adults than in both child groups. There is otherwise little developmental evidence for the selective adaptation effect, but some findings suggest that it matures across development. Despite the robustness of the effect in adults, 5- to 10-year-old children did not demonstrate changes in identification behavior after exposure to the endpoint adaptor (Sussman, 1993; Sussman \& Carney, 1989).

Perception of and adaptation to speech and non-speech sounds can be considered from a developmental perspective that is relevant for both typical development and developmental dyslexia. Although categorical perception of speech has been shown as early as infancy (Eimas et al., 1971), it continues to develop throughout childhood (Burnham et al., 1991; Walley \& Flege, 1999; Bogliotti, 2003; Hazan \& Barrett, 2000; Hoonhorst et al., 2011; Idemaru \& Holt, 2011; Nittrouer, 1999) and into adolescence (McMurray et al., 2018). Consistent identification of phonemes entails both generalization and precision. Children generalize regularities between tokens to develop more abstract rules, constructing probabilistic models of within-category (e.g., all instantiations of $/ \mathrm{b} /$ ) and across-category (differences between $/ \mathrm{b} /$ and $/ \mathrm{d} /$ ) phonetic variations 
that are allowed in their language (Panneton \& Newman, 2012; Saffran et al., 1996). Early in development there is an overall lower precision in processing acoustic cues in speech (Nittrouer \& Crowther, 1998), but since adaptation is an integral part of generalization and children are fast learners, it is possible that these adaptation processes are independent of stimulus-specific perceptual acuity. Contrasting perceptual processes with adaptation processes in typical and atypical development could shed light on the domain-specificity of perceptual adaptation and on the causal mechanisms of atypical phonological development in dyslexia.

The present study aimed to examine, in an integrated fashion, both perception and adaptation for both non-speech and speech sounds. We measured individuals' abilities to discriminate tone frequencies and to identify syllables from a place-of-articulation continuum. We also measured perceptual adaptation for both tones and speech. We compared these effects among four groups: children and adults with and without dyslexia. Such a comparison could reveal whether individuals' perceptual abilities impact the rapid learning (adaptation) processes operating on those same stimuli. Additionally, the cross-sectional design could allow for differentiating deficits in perceptual acuity from deficits in adaptation-related processes across development.

Using the outcome measures for the two tasks in relation to phonological skills, we then evaluated several causal pathways that have been proposed to explain phonological deficits in dyslexia: 1) Auditory deficit: an impairment in the perception of basic auditory cues, such as frequency, impairs speech perception, leading to poor phonological skills; 2) Domain-general adaptation deficit: a broad impairment in perceptual adaptation, evident with non-linguistic stimuli, impairs speech perception, leading to poor phonological skills; 3) Speech adaptation deficit: an impairment in adaptation to speech impairs categorical speech perception, leading to poor phonological skills. 
The current study is the first to comprehensively and developmentally characterize both auditory processing and adaptation in dyslexia across linguistic and non-linguistic domains and thus has important implications for etiological theories of this disorder.

\section{Methods}

\section{Participants}

Adults $(N=27$ with dyslexia, 17 female; $N=29$ typical readers, 15 female; age $18-41$ years, $M=$ 26.6, $S D=6.3)$ and children $(N=28$ with dyslexia, 13 female; $N=31$ typical readers, 18 female; age 7-10 years, $M=7.61, S D=0.88$ ) participated in the study (see Table 1 and Supplemental Materials for participants' behavioral characterization). Child participants were recruited through outreach to local elementary schools. Adult participants were recruited through research participant listservs at local universities as well as flyers distributed in disability-resource offices, community centers, transit stations, and other public locations. All participants met eligibility criteria, which included being a native speaker of American English; being born after at least 36 weeks' gestation; having no sensory or perceptual difficulties other than corrected vision; having no history of head or brain injury or trauma; having received no neurological, neuropsychological, or developmental disorder diagnoses; taking no medications affecting the nervous system; and having a nonverbal IQ standard score $>85$. Audiometric screening was performed for all adult participants, and participants with atypical hearing were excluded. The study was approved by the Committee on the Use of Humans as Experimental Subjects (COUHES) at the Massachusetts Institute of Technology. Adult participants provided informed, written consent to participate. For child participants, parents provided informed written consent and children provided verbal assent to participate. 


\section{Neuropsychological characterization}

In addition to completing the two experimental tasks, all participants completed a comprehensive battery of standardized reading, language, and cognitive assessments, as well as a background questionnaire (Table 1). Measures included: the Sight Word Efficiency and Phonemic Decoding Efficiency subtests of the Test of Word Reading Efficiency (Torgesen et al., 2012); the Word ID and Word Attack subtests of the Woodcock Reading Mastery Tests-Revised/Normative Update (Woodcock, 2011); the 2-Set subtest of the Rapid Automatized Naming and Rapid Alternating Stimulus Tests (RAN; Wolf \& Denckla, 2005); the Peabody Picture Vocabulary Test (Vocabulary; Dunn, Dunn, Lenhard, Lenhard, Suggate, 2015); the Elision, Blending Words, and Nonword Repetition subtests of the Comprehensive Test of Phonological Processing (Wagner et al., 1999); the Gray Oral Reading Test-4 (Oral Reading Index; Wiederholt et al., 2001); and the Matrices subtest of the Kaufman Brief Intelligence Test, Second Edition (Noverbal IQ; Kaufman, 2004). Participants were included in the dyslexia group (Dys) based on performance below the $25^{\text {th }}$ percentile on at least two out of four standardized subtests of timed or untimed word or nonword reading (Sight Word Efficiency, Phonemic Decoding Efficiency, Word ID, Word Attack). Participants were included in the typical (Typ) group based on performance at or above the $25^{\text {th }}$ percentile on all four of the above subtests. A large subset of adults $(N=20)$ and children $(N=11)$ in the Dys group also reported an external diagnosis of dyslexia. Additionally, for a large subset of children responses on a parental questionnaire reported a history of reading difficulties $(N=$ $16)$. 
Table 1. Summary Behavioral Characterization of Participants

\begin{tabular}{llll}
\hline Construct & Control & Dyslexia & Cohen's $\boldsymbol{d}$ \\
\hline \hline Children & Mean \pm SD & Mean \pm SD & 0.98 \\
\hline Age & $7.83 \pm 0.45$ & $8.41 \pm 0.73$ & 0.89 \\
\hline Nonverbal IQ & $110.31 \pm 17.43$ & $94.59 \pm 17.74$ & 2.48 \\
\hline Word ID & $11.6 \pm 9.3$ & $84.9 \pm 12.31$ & 2.67 \\
\hline Word Attack & $110.26 \pm 8.92$ & $82.42 \pm 11.72$ & 2.36 \\
\hline Sight Word Efficiency & $107.8 \pm 8.44$ & $83.79 \pm 12$ & 2.42 \\
\hline Phonemic Decoding Efficiency & $103.9 \pm 8.69$ & $79.96 \pm 11.14$ & 0.49 \\
\hline Vocabulary & $117.84 \pm 12.51$ & $110.96 \pm 12.18$ & 1.74 \\
\hline Oral Reading Index & $99.74 \pm 7.8$ & $83.9 \pm 10.45$ & 0.66 \\
\hline Blending Words & $10.97 \pm 2.04$ & $9.65 \pm 1.93$ & 1.79 \\
\hline Elision & $12.71 \pm 2.67$ & $8.3 \pm 2.16$ & 0.73 \\
\hline Nonword Repetition & $10.07 \pm 1.91$ & $8.77 \pm 1.52$ & 0.22 \\
\hline RAN 2-Set & $105.91 \pm 12.77$ & $103.03 \pm 13.81$ & 0.02 \\
\hline Adults & & & 0.48 \\
\hline Age & $26.14 \pm 6.15$ & $27.07 \pm 6.53$ & 2.48 \\
\hline Nonverbal IQ & $114.28 \pm 13.41$ & $107.96 \pm 15.18$ & 2.67 \\
\hline Word ID & $108.75 \pm 7.55$ & $89.92 \pm 9.96$ & 2.03 \\
\hline Word Attack & $102.50 \pm 7.8$ & $77.6 \pm 9.71$ & 2.76 \\
\hline Sight Word Efficiency & $109.10 \pm 13.99$ & $89.15 \pm 9.38$ & 0.96 \\
\hline Phonemic Decoding Efficiency & $104.33 \pm 7.62$ & $83.29 \pm 8.61$ & 2.18 \\
\hline Vocabulary & $114.44 \pm 7.77$ & $107.71 \pm 8.05$ & 0.8 \\
\hline Oral Reading Index & $105.45 \pm 11.98$ & $85.76 \pm 10.46$ & 0.62 \\
\hline Blending Words & $12.17 \pm 2.62$ & $10.60 \pm 2.96$ & 1.58 \\
\hline Elision & $9.23 \pm 2.07$ & $8.12 \pm 2.51$ & 1.46 \\
\hline Nonword Repetition & $9.07 \pm 2.16$ & $6.41 \pm 1.69$ & $102.04 \pm 8.47$ \\
\hline RAN 2-Set & $115.47 \pm 9.85$ & & \\
\hline Standard & & & \\
\hline
\end{tabular}

* Standard scores are presented for all the behavioral measures.

Musical training and individual differences

Individuals with musical training have demonstrated better discrimination of tones and speech than non-musicians (Amir et al., 2003; Carey et al., 2015; Gaab et al., 2005; Koelsch et al., 1999; Zuk et al., 2013, 2017). In order to examine whether the differences in performance on the two tasks could be explained by differences in musical training between groups, participants were 
asked to self-report their musical experience (number of days and years practicing a musical instruments). Musical training data was not collected in the child sample. We expected that the experiential effects of musical training on language development to be smaller in children than adults due to limited musical training.

Adult participants were divided into musician and non-musician groups based on prior musical training experience. The non-musician group had 0 years of musical training experience, and the range in the musician group was $2-26$ years (mean $=9.9$ years, $\mathrm{SD}=6.86$ years). A chisquare analysis compared differences in the frequency of musicians between the Dys and the Typ groups, and the musician group variable was included in the linear regression models for each experiment to test whether group differences in the outcome measures could be attributed to differences in musical experience.

\section{Speech in Noise}

Perceptual noise exclusion has been proposed as a fundamental deficit in dyslexia (Sperling, Lu, Manis, \& Seidenberg, 2005). It has been suggested that difficulty perceiving speech in noise is the result of impaired adaptation to repeating stimuli and perceptual anchor formation (Ahissar 2006; 2007). To establish whether there are group differences in speech-in-noise perception and to replicate previous findings, all adults in the study were administered the Quick Speech-in-Noise Test (QuickSIN; Etymotic Research; Killion et al. 2004), a measure of sentence perception in fourtalker babble. Participants heard sentences presented at $70 \mathrm{~dB}$ SPL and were instructed to repeat the sentence spoken by a female voice. Trials began with a signal-to-noise ratio (SNR) of $25 \mathrm{~dB}$ (very easy) and decreased by $5 \mathrm{~dB}$ to an SNR of $0 \mathrm{~dB}$ (extremely difficult). Participants' SNR 
scores were based on the average of the number of correctly repeated target words across eight lists of six sentences each (one per each SNR threshold).

\section{Experiment 1: Anchoring}

This experiment probed how a repeated reference tone across trials influences tone frequency discrimination, using a design modeled after Ahissar et al. (2006). Listeners' discrimination limens tend to improve when a reference stimulus is held constant throughout a session (Braida et al., 1984). Participants heard two tones and had to indicate which was the higher tone by pressing a button. There were two conditions with 70 trials each. In the no-standard condition, the frequency of both tones changed across trials in a two-down/one-up staircase procedure converging on $71 \%$ correct (with step size decreasing every four reversals from 40 to 25 to $5 \mathrm{~Hz}$ ). The lower tone was randomly selected for each trial from the interval of 1,000-1,400 Hz. The higher tone was in relation to the lower tone and based on the appropriate frequency interval indicated by subject's performance. In the standard condition, the frequency of the lower tone was constant across trials $(1,000 \mathrm{~Hz})$, and the other tone was selected as in the no-standard condition. Tone duration was 50 msec, the interstimulus interval (ISI) was $1 \mathrm{sec}$, and the initial frequency difference was $500 \mathrm{~Hz}$. The testing block was preceded by a practice block of 15 trials of tone pairs with a $1,000 \mathrm{~Hz}$ difference between the two tones. Participants had to reach an accuracy criterion in order to continue with the task: for adults the criterion was set to 0.8 (after Ahissar et al., 2006) and for children it was adjusted to 0.6 to account for worse overall performance.

Three outcome variables were analyzed for this task. Tone discrimination was calculated as the mean frequency difference in the last seven reversals (i.e., the just noticeable difference (JND)) for each condition. Because the no-standard condition used comparison tones chosen from 
the range of 1000 to 1400 versus 1000 in the standard condition, and the frequency discrimination thresholds tend to scale with the comparison frequency (e.g., Wier et al., 1977), this could lead to an artificial inflation of the advantage of the standard condition in terms of threshold. To account for this possible inflation, we divided the JND by the frequency of the comparison tone to express it as a percentage (JND \%). Accuracy of tone discrimination was calculated as the mean percentage of correct responses for each condition. Tone anchoring was indexed by the normalized difference in threshold (NTD) between the standard and no-standard conditions: $\left(\mathrm{JND}_{\text {standard }}-\mathrm{JND}_{\mathrm{no}-\text { standard }}\right) /\left(\mathrm{JND}_{\text {standard }}+\mathrm{JND}_{\mathrm{no} \text {-standard }}\right)$.

\section{Experiment 2: Selective Adaptation}

This experiment probed how phonetic context influences phonetic identification. After adapting to one end of a phonetic continuum, identification functions tend to shift towards the adapted end, reflecting a greater number of stimuli subsequently identified as belonging to the non-adapted category (Eimas \& Corbit, 1973). Participants listened to repeated canonical instances of $/ \mathrm{ba} /$ or /da/ (i.e., the continuum endpoints) and then identified stimuli from the continuum. There were eight total pre-exposure blocks to $/ \mathrm{ba} /$ or $/ \mathrm{da} /$, each containing 70 repetitions. Each pre-exposure block was followed by a block of identification trials, with each of the nine continuum steps presented once per block in random order. Participants were instructed to press a left button if they heard a /b/ and a right button if they heard a /d/. Stimuli were created by Stephens and Holt (2011); we used nine steps (\#s 2, 4, 6, 8, 10, 12, 14, 16, 18) from the original 20-step continuum. The original endpoint stimuli were recorded by a male speaker of American English, and the continuum was generated by linearly interpolating at every 5 -msec time step between the two endpoints (see Stephens \& Holt, 2011 for complete methods). 
Several outcome variables were analyzed for this task. Speech identification accuracy for the endpoint tokens was calculated as $d^{\prime}=(\mathrm{z}$ (hit: response of /b/ at step 2$)$ - (z(false alarm: response of $/ \mathrm{b} /$ at step 18)). Participants who had a $d^{\prime}=0$ were excluded from the analysis. Categorical perception of the continuum was quantified by submitting individuals' identification responses to a logistic fitting, with continuum step as the independent variable and the probability of a /b/ response as the dependent variable. This yielded coefficients for the slope and inflection point under each of the two adaptors. The values of the slope parameters were log-transformed to approach normally distributed data. The slope parameter was used as the index of categorical perception in the mediation analyses (see below), reflecting the consistency of phonetic categorization. Speech adaptation was measured at each step of the continuum as the difference in the probability of $/ \mathrm{b} /$ identification between the $/ \mathrm{ba} /$ and $/ \mathrm{da} /$ adaptors. The inflection point from the logistic fitting was analyzed as a secondary index of speech adaptation, reflecting a shift of the category boundary as a function of the adaptor. The inflection point (in terms of step number) was determined for each participant and adaptor condition by dividing the intercept estimate by the slope estimate for step.

For adults and children, the experimental measures were administered following the administration of the standard measures (80-minute battery), during the same session. The tasks were administered in the same order across all participants. Each task took 5-10 minutes to administer and the tone task was administered following the selective adaptation task. For some adult participants, the tone task was administered in a separate subsequent session.

\section{$\underline{\text { Statistical Analysis }}$}


For both experiments, outcome variables were analyzed in R v3.5.0 ( R Core Team, 2013), using identical statistical thresholds $(p<0.05)$, and random effect structures (using the package lme4 (Bates et al., 2007). Significance of fixed effects in the models was tested in an ANOVA $f$ and fitted with restricted maximum likelihood (REML) using the package lmerTest (Kuznetsova et al., 2016). Significance of the random effect in the model was tested using the rand function from lmerTest. Degrees of freedom were estimated using the Satterthwaite approximation (Kuznetsova et al., 2016; Luke, 2017). Cumming estimation plots showing effect sizes were produced using the dabestr package (Ho et al., 2019); for each of these plots, the distribution of the effect sizes and their $95 \%$ confidence intervals were obtained through nonparametric bootstrap resampling (5000 samples).

\section{Pairwise Correlation Analysis}

Spearman pairwise correlations were computed for the variables tested in the mediation models using the Hmisc package in R (Harrell Jr \& Harrell Jr, 2019). Bayesian correlations were also computed using the BayesFactor package (Morey et al., 2015) with default priors comparing a null model of no correlation with the alternative model of correlation. Bayesian models provide good precision even in smaller data sets (Lee \& Song, 2004). Importantly, Bayes factors provide a measure of how likely the data is under the null versus alternative hypothesis, allowing us to quantify and compare relative support for the existence of a relationship between each two pairs of variables. Based on the previous work, Bayes factors larger than 1 were considered to provide positive evidence (albeit weak if under 3 ) in favor of the alternative hypothesis that two variables are correlated (Jeffreys, 1998; Wetzels et al., 2011). 


\section{$\underline{\text { Mediation Analysis }}$}

Three mediation models were analyzed separately for children and adults, in both typical readers and individuals with dyslexia, as well as separately in the dyslexia group, in order to evaluate three putative causal paths proposed to explain phonological deficits in dyslexia. The mediation analysis was conducted using the lavaan package in R (Rosseel, 2014). The package estimates (a) the direct effect of the independent variables (tone discrimination, tone anchoring, and speech adaptation) on the dependent variable (phonological awareness) independently of the mediator; and (b) the indirect effect of the independent variable on the dependent variable through the mediator (categorical perception) (Hayes, 2012). The mean score of the two CTOPP phonologic measures (Elision and Blending Words) was computed and included as the dependent variable. The model was fit using a robust maximum likelihood criterion in the lavaan package and bootstrapped standard error estimates were computed to account for potential deviation from multivariate normality and for the known normality problems when testing defined mediation coefficients.

\section{Results}

\section{Experiment 1: Anchoring}

Some children did not complete this task because of below-criterion performance on the practice trials ( $N=4$ with dyslexia; $N=1$ typical readers) and two children, both with dyslexia, did not complete the task due to other reasons. Some adults discontinued the study without completing this task ( $N=2$ with dyslexia, $N=6$ typical readers).

Tone discrimination. To test for group and age differences in tone discrimination thresholds, a linear mixed-effects model was conducted with JND \% as the dependent variable. Fixed factors in the model included condition (standard vs. no-standard), age (children vs. adults) and group 
(Dys vs. Typ); the model's random effects structure included random intercepts by participants (Jaeger, 2008). The random effect of participant was significant and therefore it was included in all subsequent models that included repeated measures $\left(\mathcal{X}^{2}(1)=4.66, p=0.03\right)$. The main effect of condition was significant $\left(F(1,97.75)=18.93, \mathrm{p}<0.001, \eta p^{2}=0.16\right)$, such that JND was lower for the standard than for the no-standard condition. The main effect of group was significant $\left(F(1,98.82)=15.38, p<0.001, \eta p^{2}=0.13\right)$, such that JND was higher for Dys than Typ groups in both children and adults. The main effect of age was significant $(F(1,98.82)=$ $30.35, p<0.001, \eta p^{2}=0.23$ ), with a higher JND in the child than the adult group. The interaction effects of age x group was significant $\left(F(1,98.82)=3.99, \mathrm{p}=0.049, \eta p^{2}=0.04\right)$, with significantly higher JND in Dys children as compared to Typ children $(t(95.6)=4.14, p<0.001)$, but not in Dys adults as compared to Typ adults $(\mathrm{t}(95.6)=1.38, \mathrm{p}=0.17)$. The condition $\mathrm{x}$ age $\left(F(1,97.86)=3.38, p=0.07, \eta p^{2}=0.01\right)$, condition $\operatorname{group}\left(\mathrm{F}(1,97.75)=0.09, \mathrm{p}=0.77, \eta p^{2}=0\right)$ and condition group $x$ age $\left(F(1,97.75)=0.01, \mathrm{p}=0.82, \eta p^{2}=0\right)$ contrasts were not significant. Individual data and mean differences are shown in Figure 1A.

Accuracy. We also examined group differences in the mean accuracy (percent correct) for each condition. A linear mixed-effects model revealed that tone discrimination accuracy was significantly lower in the Dys than Typ group $\left(F(1,102)=23.99, p<0.001, \eta p^{2}=0.19\right)$ and in children than adults $\left(F(1,102)=64.06, p<0.001, \eta p^{2}=0.39\right)$. Accuracy was also higher for the standard than the no-standard condition $\left(F(1,102)=132, p<0.001, \eta p^{2}=0.56\right)$. The age $\times$ group $\left(F(1,102)=2.21, p=0.14, \eta p^{2}=0.02\right)$, condition $\mathrm{x}$ age $\left(F(1,102)=3.39, p=0.07, \eta p^{2}=0.03\right)$ or condition x group $\left(F(1,102)=1.1, p=0.3, \eta p^{2}=0.01\right)$ interactions were not significant.

Tone anchoring. The tone anchoring effect, indexed by the normalized difference in threshold (NTD), was analyzed in a $2 \times 2$ ANOVA for effects of age (children vs. adults) and group 
(Dys vs. Typ). We found a main effect of age $\left(F(1,94)=4.31, p=0.04, \eta p^{2}=0.043\right)$, such that adults demonstrated a stronger anchoring effect than children. However, there was no effect of $\operatorname{group}\left(F(1,94)=1.92, p=0.16, \eta p^{2}=.019\right)$, nor an age $\times$ group interaction $(F(1,94)=0.06, p=$ $\left.0.8, \eta p^{2}=0.001\right)$. The individual data and mean differences are shown in Figure 1B.
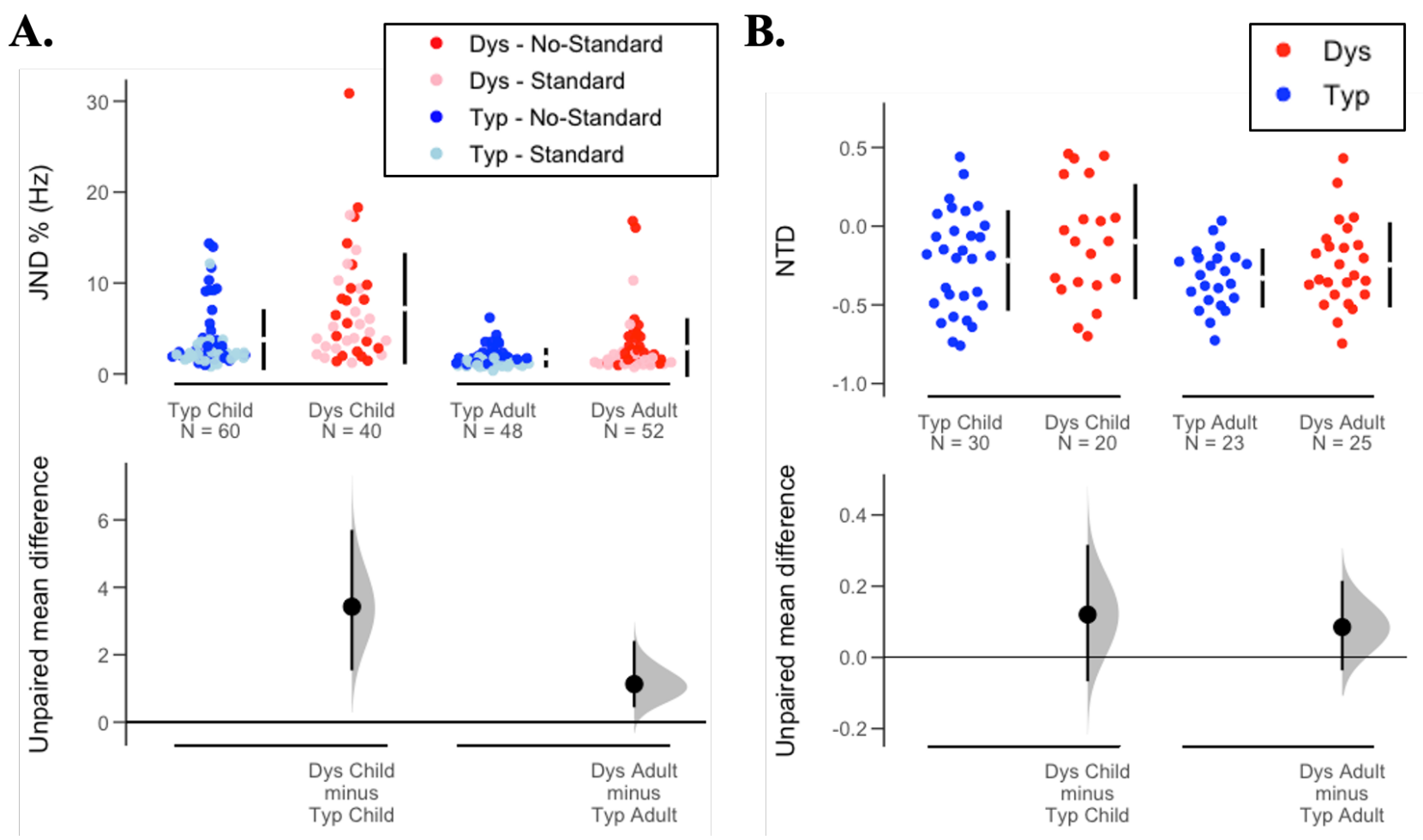

Figure 1: A. Top: Just noticeable differences (JND) in Hz expressed as percentage of comparison frequency are plotted for four participant groups (blue: typical children and adults; red: children and adults with dyslexia). Overlaid in each plot are the data from the two experimental conditions (dark circles: non-standard (NS) condition; light circles: standard (S) condition). Higher JND values indicate worse tone-frequency discrimination. B. Top: Normalized differences in threshold (NTD) are plotted for the four participant groups. Negative NTD values indicate that the threshold measured for the standard condition is lower than the threshold for the no-standard condition, which indicates anchoring. Bottom: Difference of the means, effect size, and $95 \%$ confidence interval. 


\section{Experiment 2: Selective Adaptation}

Speech Identification. We first examined group differences in the mean accuracy $(d ')$ with which participants correctly identified the $/ \mathrm{ba} /$ and $/ \mathrm{da} /$ endpoints of the continuum. Three participants (2 Dys children, 1 Dys adult) who performed at chance $\left(d^{\prime}=0\right)$ were excluded from this analysis. An ANOVA with age and group factors revealed that speech identification accuracy was significantly lower in the Dys group $\left(F(1,105)=6.35, p=0.013, \eta p^{2}=0.044\right)$ and in children $\left(F(1,105)=28.71, p<0.001, \eta p^{2}=0.198\right)$. The age $\times$ group interaction was not significant $(F(1$, $\left.105)=1.241, p=0.089, \eta p^{2}=0.021\right)$.

Categorical Perception. We next analyzed the slope parameter of the identification function as an index of categorical perception of the /ba/-/da/ continuum (Figure 2). A steeper slope indicates more consistent identification of the stimuli. One participant (Dys adult) with a slope value of zero was excluded from the analysis. Four participants ( 2 Typ children, 2 Dys children) whose curve-fitting yielded outlier inflection points ( 2 or more standard deviations above the mean) were excluded from this analysis.

A linear mixed-effects model was used to test for group and age differences in categorical perception, with slope as the dependent variable, adaptor (/ba/ or /da/), age (children vs. adults) and group (Dys vs. Typ) as fixed effects, and random intercepts by subject. The deviance parameter extracted from the logistic model was used as a weight in the LME model to correct for model fit differences across the four groups. The random effect of participant was significant and therefore it was included in all subsequent models $\left(\mathcal{X}^{2}(1)=23.51, p<0.001\right)$.

There was a significant main effect of group $\left(F(1,97.41)=3.97, p=0.049, \eta p^{2}=0.04\right)$, with steeper slopes for the Typ group as compared to the Dys group, suggesting increased ambiguity in individuals with dyslexia in identifying /b/ for both /ba/ and /da/ adaptors. There was 
also a significant main effect of age on categorical perception $(F(1,97.41)=101.78, p<0.001$, $\left.\eta p^{2}=0.35\right)$, with children having shallower slopes than adults overall. The adaptor $(F(1,117.13)$ $\left.=0.17, p=0.68, \eta p^{2}=0\right)$ main effect and the group $\times$ adaptor $\left(F(1,117.13)=0.26, p=0.61, \eta p^{2}\right.$ $=0)$, adaptor $\times$ age $\left(F(1,117.13)=0, p=0.95, \eta p^{2}=0\right)$, group $\times$ age $(F(1,97.41)=3.23, p=0.08$, $\left.\eta p^{2}=0.3\right)$, and group $\times$ age $\times$ adaptor $\left(F(1,96.51)=2.15, p=0.15, \eta p^{2}=0.02\right)$ interaction effects were not significant. Although the group $\times$ age interaction did not achieve significance, due to the borderline $p$ value (0.08) we examined the group effect in children and adults separately. A Tukey post-hoc comparison revealed significantly larger slopes in Typ children as compared to Dys children $(t(8837)=3.03, p=0.002)$, but no significant group differences in adults $(t(3629)=0.13$, $p=0.91)$.
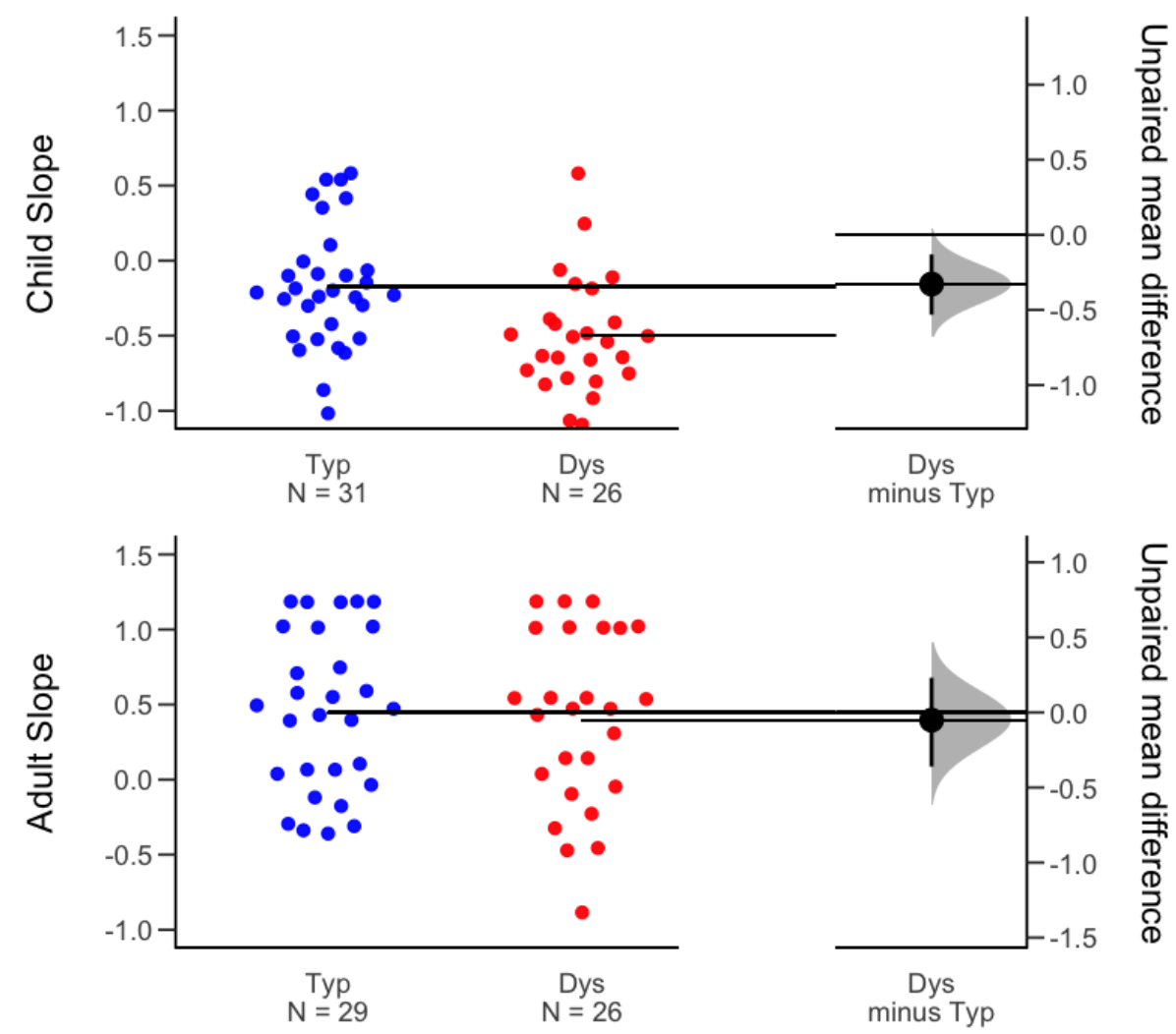
Figure 2: Log-transformed slopes of the identification functions calculated for the selective adaptation experiment in children (top) and adults (bottom). On the right, estimation plots show the mean differences in slopes between the dyslexia and typical groups (i.e., effect sizes: black dots), mean values for each group indicated by the horizontal bars, the distribution of the effect sizes of the mean differences, and their 95\% confidence intervals (black bars).

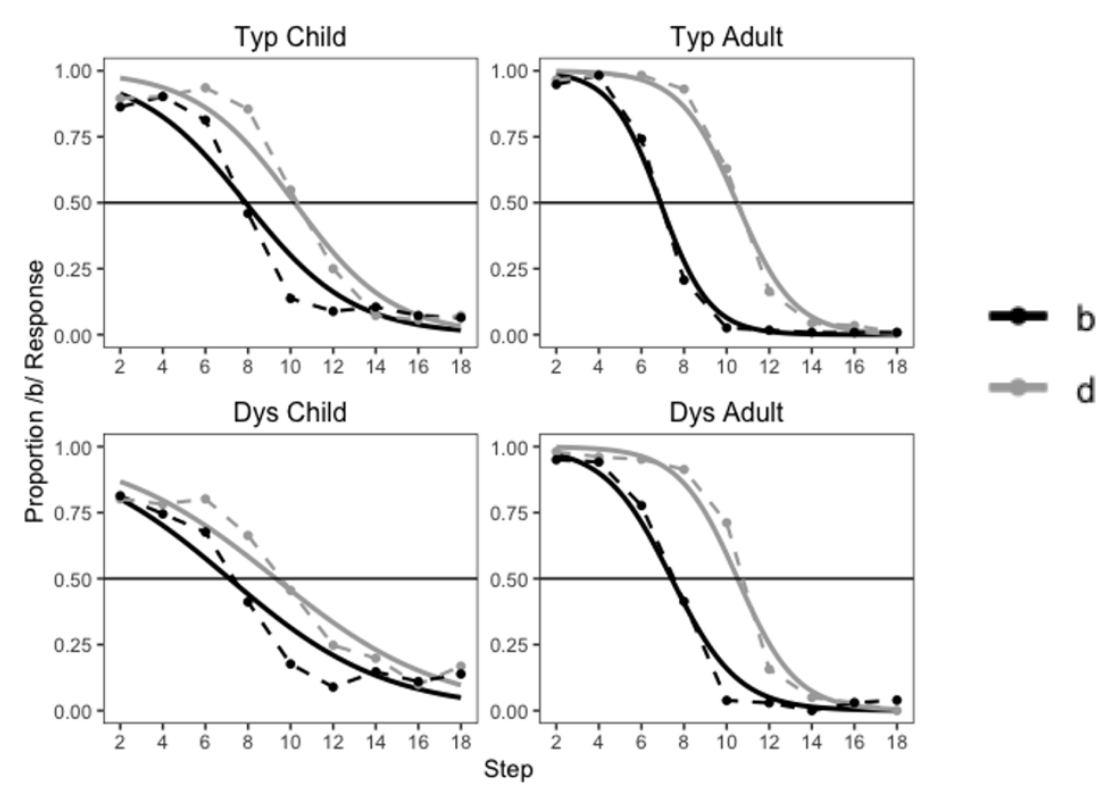

Figure 3: The category boundary shift due to selective adaptation is evident from the proportion of /b/ responses as a function of the /ba/ (black) or /da/ (gray) adaptor. Points show empirical raw data. Solid lines show predictions of the model used to obtain corrected estimates of the slope and inflection point.

Speech adaptation. Adaptation to speech is revealed by differences in the probability of a /b/ response between the two adaptors for each step (Figure 4). Differences in speech adaptation by group, age, and step were examined. An ANOVA revealed a significant group $\times$ step interaction effect $\left(F(1,972)=2.02, p=0.04, \eta p^{2}=0.03\right)$. A Tukey post-hoc comparison revealed significantly higher adaptation for Typ than for Dys groups in both children and adults for step 8 only $(t(972)=$ 4.23, $p<0.001)$. The age $\times$ step interaction effect $\left(F(1,972)=7.3, p<0.001, \eta p^{2}=0.03\right)$ was also significant, with higher adaptation for adults than children at steps $8(t(972)=6.62, p<0.001)$ and 
$10(t(972)=6.18, p<0.001)$ only. The age $\times \operatorname{group}\left(F(1,972)=0, p=0.96, \eta p^{2}=0\right)$ and the age $\times$ group $\times \operatorname{step}\left(F(8,972)=0, p=0.96, \eta p^{2}=0\right)$ interaction effects were not significant.

A secondary measure of speech adaptation was the continuum step at which the inflection point of the identification function was located as a function of /ba/ vs. /da/ adaptor. The shift of these curves towards the adaptor is evident in Figure 3. An LME model was constructed with inflection step as the dependent variable and group, age, and adaptor as the independent variables. Confirming an adaptation effect, there was an overall significantly earlier (i.e., closer to /ba/) inflection point under the $/ \mathrm{ba} /$ adaptor than under the $/ \mathrm{da} /$ adaptor $(F(1,148.56)=128.59, p<0.001$, $\left.\eta p^{2}=0.46\right)$. The age $\times$ adaptor effect was also significant, with significantly later inflection in adults for the /da/ adaptor, but not for the $/ \mathrm{ba} /$ adaptor $\left(F(1,148.56)=10.73, p=0.003, \eta p^{2}=0.02\right)$. The $\operatorname{group}\left(F(1,133.19)=2.51, p=0.12, \eta p^{2}=0.02\right)$, age $\left(F(1,133.19)=0.33, p=0.57, \eta p^{2}=\right.$ $0.002)$ main effects and the group $\times$ age $\left(F(1,133.19)=1.98, p=0.16, \eta p^{2}=0.02\right)$, group $\times$ $\operatorname{adaptor}\left(F(1,148.56)=0.08, p=0.9, \eta p^{2}=0\right)$, and $\operatorname{group} \times \operatorname{age} \times \operatorname{adaptor}(F(1,148.56)=2.18, p$ $\left.=0.14, \eta p^{2}=0.01\right)$ interaction effects were not significant. 


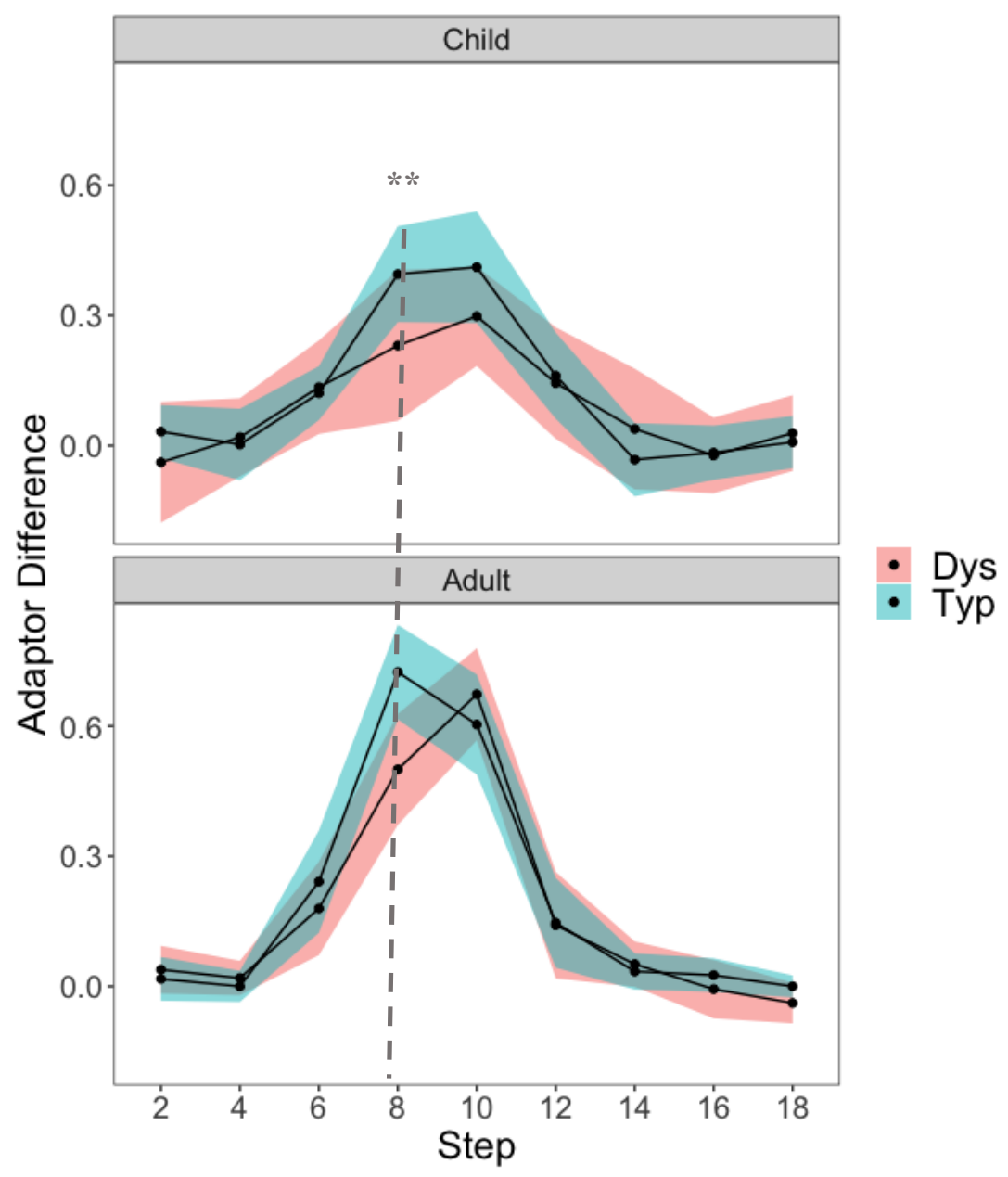

Figure 4: Speech adaptation effects (proportion of $/ \mathrm{b} /$ responses under the /da/ adaptor minus under the /ba/ adaptor) and $95 \%$ confidence intervals are plotted as a function of continuum step, for adults (top) and children (bottom), and for individuals with (red) and without (green) dyslexia. At step 8, there is a significant difference in speech adaptation between dyslexia and typical groups in both adults and children.

\section{Musical Training and Speech-in-Noise Perception}

A chi-square test of independence was performed to determine whether one group of adult participants contained a greater proportion of musicians than the other. There was a significantly greater proportion $\left(\chi^{2}(1)=5.08, p=0.02\right)$ of musicians in the Typ group $(46 \%)$ than in the Dys group (13\%). A regression model for the significant effects for both experiments revealed that 
group was a robust predictor of outcome beyond musicianship for tone discrimination $(F(1,31)=$ 7.68, $p=0.008)$ and for speech adaptation differences at step $8(F(1,31)=9.6, p=0.004)$, but not for categorical perception $(F(1,31)=0.28, p=0.6)$ or tone anchoring $(F(1,31)=0, p=0.1)$. Musical training was a significant predictor of tone discrimination $(F(1,31)=7.08, p=0.01)$ and categorical perception $(F(1,31)=4.97, p=0.03)$, but not of tone anchoring $(F(1,31)=0.36, p=$ $0.55)$ or speech adaptation $(F(1,31)=2.4, p=0.13)$. A $t$-test comparing performance on the speechin-noise test between the adult Dys and Typ groups revealed a significantly higher threshold in Dys $(t(31.23)=2.16, p=0.04)$. This means that individuals with dyslexia required more favorable signal-to-noise ratio to understand speech in noise, as compared to typical readers.

\section{Pairwise Correlation Analysis}

Spearman rho pairwise correlations were computed for the five variables tested in the mediation models: tone discrimination, tone anchoring, categorical perception, speech adaptation, and phonological awareness. This analysis was performed in children $(N=55)$ and adults $(N=50)$ separately (Table 2), as well as in the Typ and Dys groups separately (Supplemental Table 1). In children, there were significant negative correlations of tone discrimination with phonological awareness and categorical perception, with higher discrimination thresholds (worse performance) being associated with poorer phonological awareness and shallower categorical-perception slopes. The association of tone discrimination with anchoring, however, was positive, indicating stronger anchoring effects in children with worse tone discrimination. More categorical speech perception was associated with stronger speech adaptation. No other correlations were significant, but there was a positive association (small effect size) between phonological awareness and categorical perception. In adults, the only significant association of tone discrimination was with phonological 
awareness, with better phonological awareness being associated with lower discrimination thresholds (better performance). Better phonological awareness skills were also associated with more categorical perception and greater speech adaptation. No other correlations were significant, but there was a negative association (small effect size) between tone anchoring and tone discrimination, and a positive association between tone anchoring and speech adaptation.

When comparing the correlation patterns between the Typ and Dys groups (Supplemental Table 1), using Bayes factors (BF) to evaluate the evidence against the null hypothesis of no significant association between each two variables, there were several notable differences. Better phonological awareness was associated with better tone discrimination in typical children, typical adults, and adults with dyslexia $(\mathrm{BF}$ 's $>1)$, but not in children with dyslexia $(\mathrm{BF}=0.51)$. In typical children, there was a negative association between speech adaptation and phonological awareness $(\mathrm{BF}=1.39)$, suggesting reduced adaptation in those children who had better phonological skills. This association was positive in both children $(\mathrm{BF}=1.34)$ and adults with dyslexia $(\mathrm{BF}=4.77)$ and near zero for the typical adults $(\mathrm{BF}=0.46)$. Children with dyslexia who had better tone frequency discrimination also had better categorical perception for speech $(\mathrm{BF}=5.88)$, but there was no relationship between the two measures in the other three groups (BF's $<0.56)$. Finally, better speech categorization was associated with increased selective adaptation in all the groups $(\mathrm{BF}$ 's $>1)$, except children with dyslexia $(\mathrm{BF}=0.59)$. 
Table 2: Pairwise correlations among the five variables tested in the mediation models. Bayes factors are displayed in parentheses. Adult data is shown below the diagonal (white) and child data is shown above the diagonal (grey).

\begin{tabular}{|c|c|c|c|c|c|}
\hline & $\begin{array}{c}\text { Tone } \\
\text { discrimination }\end{array}$ & $\begin{array}{c}\text { Tone } \\
\text { anchoring }\end{array}$ & $\begin{array}{c}\text { Categorical } \\
\text { perception }\end{array}$ & $\begin{array}{c}\text { Speech } \\
\text { adaptation }\end{array}$ & $\begin{array}{c}\text { Phonological } \\
\text { awareness }\end{array}$ \\
\hline $\begin{array}{c}\text { Tone } \\
\text { discrimination }\end{array}$ & -- & $\begin{array}{c}-0.29^{*} \\
(\mathrm{BF}=1.22)\end{array}$ & $\begin{array}{c}-0.35^{*} \\
(\mathrm{BF}=8.14)\end{array}$ & $\begin{array}{c}0.15 \\
(\mathrm{BF}=0.49)\end{array}$ & $\begin{array}{c}-0.39^{* *} \\
(\mathrm{BF}=12.01)\end{array}$ \\
\hline $\begin{array}{c}\text { Tone } \\
\text { anchoring }\end{array}$ & $\begin{array}{c}-0.43^{*} \\
(\mathrm{BF}=0.77)\end{array}$ & -- & $\begin{array}{c}-0.09 \\
(\mathrm{BF}=0.4)\end{array}$ & $\begin{array}{c}0.09 \\
(\mathrm{BF}=0.37)\end{array}$ & $\begin{array}{c}0.06 \\
(\mathrm{BF}=0.36)\end{array}$ \\
\hline $\begin{array}{c}\text { Categorical } \\
\text { perception }\end{array}$ & -0.15 & -0.11 & -- & $0.39^{* *}$ & $\begin{array}{c}0.20 \\
(\mathrm{BF}=7.95)\end{array}$ \\
\hline $\begin{array}{c}\text { Speech } \\
\text { adaptation }\end{array}$ & $\begin{array}{c}\mathrm{BF}=0.18 \\
(\mathrm{BF}=0.44)\end{array}$ & $\begin{array}{c}0.13 \\
(\mathrm{BF}=0.91)\end{array}$ & $\begin{array}{c}0.10 \\
(\mathrm{BF}=0.66)\end{array}$ & -0.05 \\
\hline $\begin{array}{c}\text { Phonological } \\
\text { awareness }\end{array}$ & -0.26 & $\begin{array}{c}0.07 \\
(\mathrm{BF}=3.04)\end{array}$ & $\begin{array}{c}0.31 * \\
(\mathrm{BF}=0.0 .37)\end{array}$ & $\begin{array}{c}0.16 \\
(\mathrm{BF}=2.28)\end{array}$ & $\begin{array}{c}\mathrm{BF}=0.37) \\
(\mathrm{BF}=2.51)\end{array}$ \\
\hline
\end{tabular}

$* * * p<0.001, * * p<0.01, * p<0.05$ Note: uncorrected $\mathrm{p}$-values are shown. Correlation coefficients are Spearman rho.

\section{Tone Anchoring and Speech Adaptation in Typical Adults}

There was a positive association between tone anchoring and speech adaptation in typical adults $(\mathrm{BF}=1.13)$, but not in the other three groups $(\mathrm{BF}$ 's $=0.41-0.59)$. To probe whether this effect would suggest that similar mechanisms support adaptation in the tone anchoring and selective adaptation tasks, we ran a separate correlation between the two variables in typical adults after partialling out several covariates. First, to control for differences in stimulus-specific perceptual processes, tone discrimination was regressed out from tone anchoring, and categorical perception from speech adaptation. Next, since it was proposed as a putative mechanism to explain anchoring deficits on the tone task in dyslexia (Ahissar, 2007), phonological memory was partialled out from the two adaptation variables. Finally, since noise exclusion has been proposed as a primary domain-general perceptual deficit in dyslexia (Ahissar et al., 2006; Sperling et al., 2005; Ziegler et al., 2009), performance on the speech-in-noise measure was regressed out from the two 
adaptation measures. After controlling for these covariates, there was a significant association between speech adaptation and tone anchoring in typical adults $(\mathrm{r}=.43, \mathrm{p}=.046,95 \%$ CI $[.01$, $.72])$.

\section{Mediation Analysis}

We tested three mediation models corresponding to the three hypotheses for each age group across reading levels (Figure 5) and separately in the Dys groups (Supplemental Figure 1). For all three hypotheses, both the adult and the child models provided a good fit to the data: comparative fit index $(\mathrm{CFI})=1.00$, Tucker-Lewis index $(\mathrm{TLI})=1.00$, and root mean square error of approximation $($ RMSEA $)=0$. Figure 5 displays the estimated coefficients. For each of the models tested below, we report the estimate $(b)$, p-value $(p)$, and the bias-corrected and accelerated confidence interval (BCa CI) in [brackets].

For hypothesis 1 (auditory deficit), adult results revealed a significant direct effect from tone discrimination to phonological awareness $(b=-0.42, p=0.007,[-0.72,-0.12])$, but no significant indirect effect via categorical perception $(b=0.03, p=0.63$, $[-0.09,0.15])$. For Dys adults, the direct effect between tone discrimination and phonological awareness was significant $(b=-0.04$, $p=0.02,[-0.67,-0.06])$, but there was no significant mediation effect $(b=0.07, p=0.57,[-0.16$, $0.29])$. Similarly, for all children, there was a significant direct effect $(b=-0.21, p=0.01,[-0.36$, $-0.05])$, but not a significant mediation effect $(b=-0.02, p=0.55,[-0.08,0.04])$. There were no significant effects for Dys children (direct: $b=0.05, p=0.62,[-0.14,0.23]$; indirect: $b=-0.03, p$ $=0.64,[-0.13,0.08])$.

For hypothesis 2 (domain-general adaptation deficit), neither direct effects from tone anchoring to phonological awareness $(b=0.92, p=0.54,[-2,3.85])$ nor indirect effects through categorical 
perception $(b=-0.21, p=0.69,[-1.2,0.77])$ were significant in all adults or in Dys adults only (direct: $b=1.61, p=0.392,[-2.07,5.28]$; indirect: $b=-0.94, p=0.45,[-3.34,1.47])$. In children there were also no significant direct $(b=0.66, p=0.48,[-1.18,2.51])$ or indirect effects $(b=-0.17$, $p=0.507,[-0.65,0.32])$ for all children and in Dys children only (direct: $b=1.02, p=0.3,[-0.92$, 2.97]; indirect: $b=-0.03, p=0.81,[-0.25,0.19])$.

Finally, for hypothesis 3 (speech adaptation deficit), the adult model showed no significant $\operatorname{direct}(b=9.41, p=0.085,[-1.28,20.1])$ or mediation $(b=2.66, p=0.21,[-1.39,6.71])$ effects of speech adaptation on phonological awareness. In the Dys adults, the direct effect was significant $(b=16.13, p=0.04,[0.74,31.53])$, but the indirect effect was not significant $(b=6.1, p=0.17,[-$ $-2.53,14.71])$. For children, there was no significant direct effect of speech adaptation on phonological awareness $(b=-0.18, p=0.97,[-9.97,9.6])$ or mediation effect $(b=2.88, p=0.18$, $[-1.34,7.1)$. Similarly, in Dys children there were no significant direct $(b=7.9, p=0.07,[-0.76$, $16.55])$ or indirect $(b=-0.03, p=0.97,[-1.48,1.41])$ effects.

In sum, there were no significant mediation effects across all models. Instead, there were significant direct paths between tone discrimination and phonological awareness across both age groups, and between speech adaptation and phonological awareness in adults with dyslexia only. Similar results were obtained when the mediation effects were tested separately in the dyslexia group (Supplemental Figure 1). 


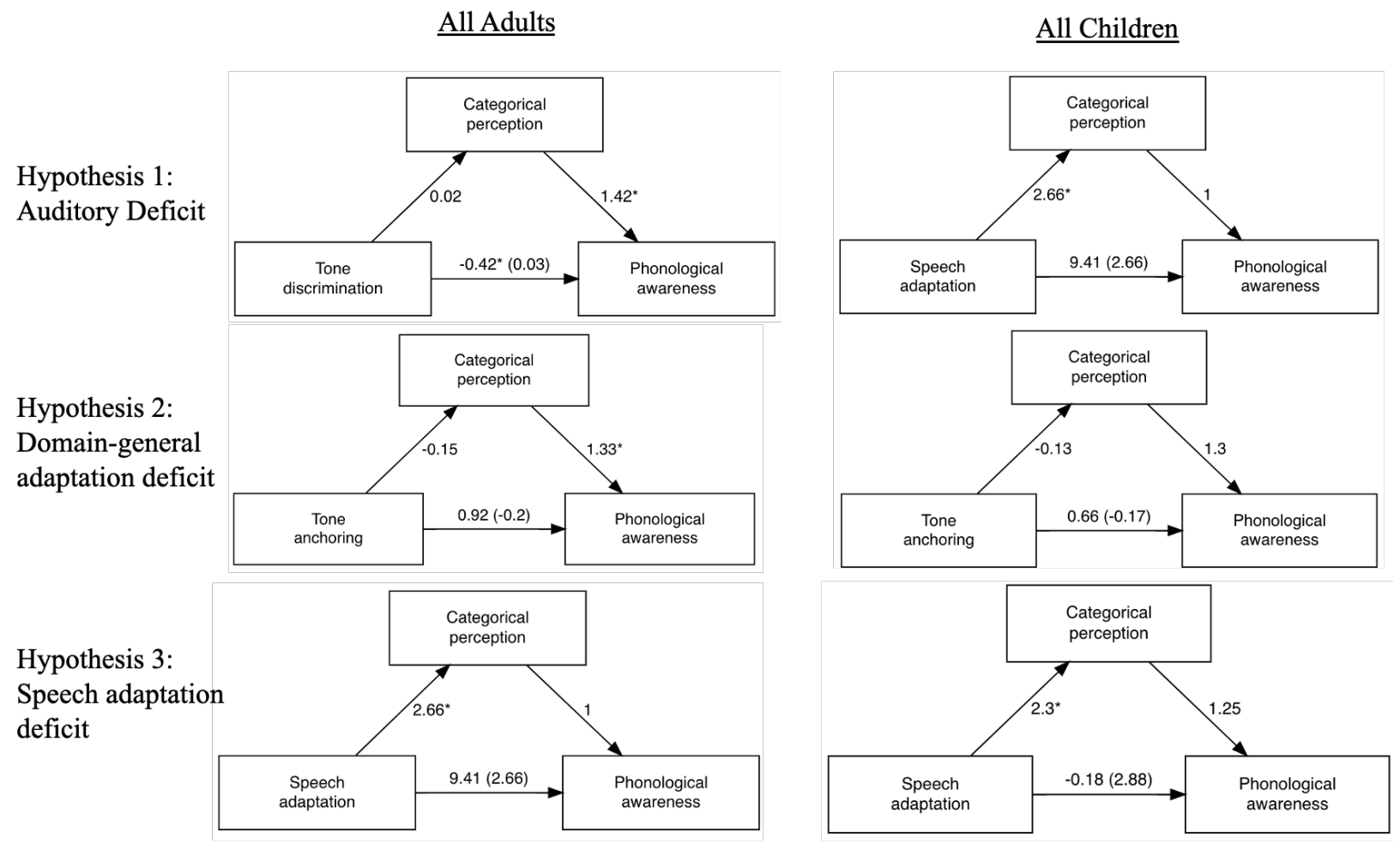

Figure 5. Three putative causal explanations for phonological deficits in dyslexia are tested with mediation models in children (right) and adults (left). Note: ${ }^{*} \mathrm{p}<0.05$. 


\section{Discussion}

According to several influential theoretical frameworks, phonological deficits in dyslexia result from reduced sensitivity to acoustic cues that are essential for the development of robust phonemic representations (Goswami, 2011; Hornickel \& Kraus, 2013; Tallal, 1984). Alternative accounts suggest that individuals with dyslexia are impaired in auditory rapid adaptation processes (Ahissar, 2007). Here, we tested these theoretical formulations using a non-linguistic tone-anchoring task and a linguistic selective adaptation task in children and adults with and without dyslexia. We found that children and adults with dyslexia were impaired in their categorization of both tones and speech sounds, and that perception was less categorical in children, but not in adults, with dyslexia. Despite these broader perceptual deficits, adaptation deficits to repeating stimuli were evident for speech stimuli, but not for tone stimuli. Thus, in contrast to previous suggestions, adaptation deficits appear not to be pervasive across domains, but to be specific to auditory linguistic stimuli.

The first goal of the study was to compare developmental differences in auditory perception of non-linguistic and linguistic cues in dyslexia. Consistent with previous findings (Halliday \& Bishop, 2006; Marshall et al., 2001; Noordenbos \& Serniclaes, 2015; Vandermosten et al., 2010; Waber et al., 2001), we found support for an auditory perceptual deficit in the discrimination of spectral and spectrotemporal acoustic cues for tones and speech, respectively. In previous reports, both adults and children with dyslexia have demonstrated poor tone frequency discrimination (Christmann et al., 2015; Grube et al., 2014; Marshall et al., 2001; Ramus, 2003; Rosen, 2003; Steinbrink et al., 2019; see Witton et al., 2019 for a review). These impairments were more pronounced in children than in adults, suggesting that the perceptual differences in individuals with dyslexia are not merely the result of reduced reading experience. 
The ability to make judgments about pure-tone frequencies rests on the fidelity of sound encoding from the earliest stages of the auditory system, including the auditory brainstem that synchronizes to frequency information in the acoustic stream (e.g., Rose et al., 1967). Brainstem recordings revealed delayed and more variable responses to sound in children and adults with dyslexia (Banai et al., 2009; Basu et al., 2010; Hornickel et al., 2011; Hornickel \& Kraus, 2013). Less stable sound representations may result in less efficient adaptation to sound statistics (Chandrasekaran et al., 2009), ultimately leading to deficits in forming stable representations of meaningful sound categories such as phonemes. Moreover, to the extent that the tone-judgment task engages mechanisms of pitch perception distinct from spectral analysis (Schneider \& Wengenroth, 2009), differences in the structure or function of pitch-sensitive cortical regions (Griffiths \& Hall, 2012) could explain altered tone perception. Additionally, or alternatively, top-down linguistic and cognitive systems important for fine-tuning lower-level sound representations may exert causal influences on sound processing and lead to reduced fidelity of sound representations in dyslexia. Therefore, psychophysical deficits in dyslexia could manifest due to subcortical or cortical auditory dysfunction or through an interaction with higher-level cognitive processes. Indeed, both lower-level deficits in phase locking to sound in the auditory pathway (Goswami, 2011) and higher-level deficits in working memory that impose constrains during performance of complex auditory tasks (Ahissar, 2007) have been proposed. The latter proposal, however, predicts deficits in the extraction of regularity rather than in perceptual judgments about (non-repeating) stimuli.

We found that speech identification (of the continuum endpoints) was impaired in both adults and children with dyslexia, and that perception was less categorical in children with dyslexia only. Differences in the magnitudes of group effects could be due to developmental factors. There is a developmental reorganization in phonetic representation towards more categorical perception 
into late childhood (Hazan \& Barrett, 2000; McMurray et al., 2018; Nittrouer, 1992, 2002; Nittrouer \& Miller, 1997; Slawinski \& Fitzgerald, 1998) and there is some evidence for a delay in such organization in individuals with dyslexia (Vandermosten et al., 2010; Vandermosten et al., 2011). Only one study so far has directly compared auditory processing in dyslexia in adults and children. That study found impaired categorization of speech and non-speech stimuli varying in spectrotemporal transitions in Dutch-speaking adults (Vandermosten et al., 2010) and 11-year-old children (Vandermosten et al., 2011), with similar effect sizes for both age groups. These studies used discrimination tasks, which are typically more sensitive than the identification tasks used in the current study and may be more sensitive to group effects in adults (Noordenbos \& Serniclaes, 2015). This suggests that the broad impairments in dyslexia in discriminating spectral and spectrotemporal cues in both linguistic and non-linguistic stimuli attenuate across development, but do not reach typical levels.

Interestingly, there were no significant relationships between tone frequency discrimination and categorical speech perception in any of the groups except for children with dyslexia, who showed a significant positive association. Furthermore, only in this group were there no associations between tone discrimination and phonological awareness. This suggests that rather than capturing similar perceptual processes related to auditory cue processing important for phonological development, the tone and speech judgment tasks are linked by an underlying lowlevel perceptual deficit that impairs task performance in children with dyslexia, but not in typical readers or in adults.

For comprehensiveness, given previous findings of superior tone and speech discrimination performance in individuals with musical experience (e.g., Magne et al., 2006; Moreno, 2009; Schön et al., 2004; Zuk et al., 2013), we tested whether dyslexia effects in the 
current study could be explained by differences in musical practice. Although musical training experience was positively associated with perceptual acuity in both tasks, differences in musical experience between adults with and without dyslexia did not explain group differences in task performance. Similarly, we were able to replicate previous literature (Ahissar et al., 2006; Amitay et al., 2002; Sperling et al., 2005) on speech-in-noise processing impairments in our adults with dyslexia.

The second goal of the study was to investigate whether dyslexia is associated with diminished domain-general auditory adaptation. We found clear evidence of diminished adaptation only for speech stimuli in both children and adults. Although there were no significant group differences in the overall inflection step, individuals with dyslexia showed reduced adaptation at a midway, most ambiguous step, on the $/ \mathrm{b} /-/ \mathrm{d} /$ continua. This suggests that adaptation differences in dyslexia are subtle and occur at the point of highest perceptual uncertainty, when the adaptation effect is most pronounced in typical readers.

For the tone anchoring measure of nonlinguistic adaptation, all groups exhibited significant adaptation of comparable magnitudes. This finding is in contrast to those of previous studies using this paradigm, which observed reduced or absent anchoring effects in dyslexia (Ahissar et al., 2006; Oganian \& Ahissar, 2012). Importantly, the current study is the first to apply the anchoring paradigm in English speakers and in both adults and children. Only one published study to date attempted to replicate the anchoring results using an identical paradigm. Similar to the current results, a study from the Netherlands found worse tone discrimination in adults with dyslexia as compared to controls, but no differences between the groups in terms of the perceptual benefit derived from the repetitive presentation of a reference stimulus (Wijnen et al., 2012). Thus, to date, most support for the anchoring deficit theory of dyslexia comes from studies in Hebrew focusing 
on adolescents with broader learning difficulties (Ahissar et al., 2006) and on adults with specific reading impairments (Oganian \& Ahissar, 2012).

Whereas the current study contradicts the anchoring hypothesis by failing to replicate the original findings (Ahissar et al., 2006), additional studies have reported deficits in the extraction of stimulus regularity across different non-linguistic perceptual and perceptual-motor tasks (BenYehudah \& Ahissar, 2004; Lum et al., 2013; Menghini et al., 2008; Stoodley et al., 2008). Others, however, have failed to find measurable differences between individuals with and without dyslexia using such paradigms (Agus et al., 2014; Gabay \& Holt, 2018). Furthermore, a systematic metaanalysis investigating whether implicit learning (including procedural and statistical learning) deficits are a cause of developmental dyslexia concluded that there is weak and insufficient evidence in support of domain-general implicit learning impairments in dyslexia (West et al., 2021). The inconsistencies in findings could be the result of a number of factors, such as orthography, participant characteristics, and age. For example, all the positive findings using the anchoring tone task were in conducted in Hebrew (Ahissar et al., 2006), but studies in Dutch (Wijnen et al., 2012), French (Agus et al., 2014), and English (Gabay \& Holt, 2018) have failed to replicate the findings. They do, however, point convincingly against broad deficits in perceptual adaptation as the core deficit in dyslexia, underlying a range of behavioral symptoms, since such deficits would then be expected in all individuals with dyslexia.

Our results of attenuated speech adaptation effects in adults and children with dyslexia as compared to those in the typically-reading groups suggest domain specificity for adaptation deficits in dyslexia. Deficits in categorical speech perception point to greater perceptual variability in processing the /ba/ and /da/ stimuli. As discussed above, such deficits in speech categorization have been consistently reported in individuals with dyslexia. The shift in category boundary in the 
speech adaptation task is explained in terms of distributional learning, where the non-variable distribution of the repeated stimulus narrows the range and distribution of the perceptual representation of this stimulus (Kleinschmidt \& Jaeger, 2016). Since the narrowing of the cue distribution relies on biasing by the exemplar adaptor, attenuated adaptation is likely a result of diminished ability to perceive the exemplar as such in individuals with dyslexia, rather than as the result of a failure to extract perceptual trial-by-trial distributional regularities.

There is some evidence, however, that in other paradigms individuals with dyslexia can exhibit impaired perceptual learning despite intact perception. A study using a distorted speech recognition task with orthographic feedback in college students demonstrated that students with dyslexia benefitted to a lesser extent from training as compared to the controls despite an equivalent baseline accuracy (Gabay \& Holt, 2021). These findings suggest that impaired adaptation for speech can be independent of baseline speech deficits. It may be that the relation of perception to learning changes when high-level lexical knowledge is involved.

Differences in adaptation deficits between the tone anchoring and the selective adaptation tasks could be partially explained by the different demands each task places on participants. In previous studies, poor anchoring performance on the tone anchoring task has been interpreted in terms of working memory deficits that constrain the extraction of pattern regularity in individuals with dyslexia (Ahissar, 2007). The selective adaptation task, on the other hand, is considered to be low-level and automatic, not affected by working memory demands (Baart \& Vroomen, 2010; Samuel \& Kat, 1998). In support of shared adaptation mechanisms underlying both tasks, we found a significant correlation between speech adaptation and tone anchoring in typical adults, after controlling for stimulus-specific performance, working memory, and signal-in-noise processing. Therefore, it appears that both tasks engaged domain-general rapid adaptation processes to 
repeating stimuli and that these processes are preserved in individuals with dyslexia. In order to more conclusively establish that perceptual deficits in dyslexia are specific to linguistic stimuli, however, future studies should better align task demands. This could be done, for example, by utilizing a selective adaptation task for tones, or alternatively, an anchoring task for speech continua.

We interpret the results to mean that behavioral adaptation deficits in dyslexia are speechspecific, arising as the result of weaker discrimination of acoustic categorical differences relevant for speech. Although the causal nature of this relation cannot be established based on correlational evidence, we did find, in support of this interpretation, that better speech categorization was associated with increased selective adaptation in children with dyslexia, but not in typical readers or adults with dyslexia. Better tone discrimination was also associated with better speech categorization, suggesting that the ability to discriminate lower-level non-linguistic acoustic cues is related to the development of categorical speech perception. With increased reading experience , differences in frequency discrimination have no direct relations with processing spectrotemporal cues in speech. In the subsequent analysis, we tested causal links between these perceptual deficits and phonological awareness.

The third goal of the study was to evaluate several causal hypotheses about the relationships between auditory processing and phonological deficits in dyslexia. The common thread across the perceptual theories of phonological deficits in dyslexia is that a primary deficit in lower-level auditory or learning mechanisms manifests in less precise speech discrimination, leading to poor phonological development. Our findings did not support these hypothesized mediated pathways: speech slope was not a significant mediator of the association between frequency discrimination, anchoring, or adaptation and phonological awareness. This suggests that 
auditory and speech adaptation deficits are epiphenomenal to phonological deficits in individuals with dyslexia, but that they do not share a causal relationship (Bishop, 2013). Previous studies aiming to characterize the underlying mechanisms of a phonological deficit in dyslexia have reached a similar conclusion (Manis et al., 1997; Ramus, 2003; Rosen, 2003). For example, in one study, less precise neural differentiation of speech was related to familial risk of dyslexia, but not to actual reading outcomes in children (Vandermosten et al., 2020). These findings support the cooccurrence of, but not causal links between, atypical speech processing and dyslexia.

Alternatively, it is possible that the causal relations between auditory processing and phonemic perception are specific to one acoustic domain, but not others. For example, a longitudinal study demonstrated that growth in phonological skills in children with and without dyslexia was predicted by individual differences in discrimination of rise time cues across a range of non-linguistic stimuli (Goswami et al., 2020). The study, however, did not test mediation links with categorical speech perception, but only focused on the direct pathways between tasks' sensitivity to rise time and phonological skills. These direct associations between tone discrimination and phonological skills are also supported by the current study.

Another possible and not mutually exclusive explanation is that categorical speech perception is only one of the potential mediators of the effects of basic auditory perception on phonological skills. Phonological deficits in dyslexia arise through interactions among multiple risk and protective factors (Ozernov-Palchik et al., 2016; Pennington, 2006). The occurrence of multiple perceptual and cognitive deficits in dyslexia could be due to partly-shared etiology that affects multiple neural systems. More complex structural equation models are needed, therefore, to model the complex and multi-factorial interactions between sensory, perceptual, and higherlevel cognitive processes (e.g., Boets et al., 2008). Furthermore, the need to apply such models to 
neural data is evident from the intriguing findings of broad deficits in rapid neural adaptation in adults and children with dyslexia across a range of linguistic and non-linguistic, auditory and visual, stimuli (Perrachione et al., 2016; Peter et al., 2019). The absence of evidence for behavioral adaptation deficits to some of these stimuli points to the enhanced sensitivity of neural measures to subtle differences that are not evident in behavior or that arise only under adverse conditions or challenging task demands (Banai \& Ahissar, 2006). Taken together, and in light of these considerations, our findings lay a foundation for future studies, with larger sample sizes, examining causal relationships among perceptual, cognitive, and neural factors in explaining phonological deficits in dyslexia across development, starting as early as preschool.

Our findings have important implications for understanding how auditory perception and adaptation interact in typical development. This is the first study to probe these relations using cross-sectional adult and child data. Our findings of worse performance on tone frequency discrimination and on speech categorization tasks in children support previous observations of a long developmental trajectory of both frequency discrimination (e.g., Jensen \& Neff, 1993; Maxon \& Hochberg, 1982; Thompson et al., 1999) and categorical speech perception (e.g., Hazan \& Barrett, 2000; McMurray et al., 2018; Nittrouer, 1992, 2002). In terms of adaptation, there were lower effects in children as compared to adults in both tasks. Intriguingly, in typical children, but not in adults, tone anchoring was correlated with tone discrimination, and speech adaptation with speech categorization. This suggests that early in development adaptation effects are closely linked with the performance of the perceptual system and are therefore domain specific. In contrast, in typical adults, greater anchoring effects for tones was associated with stronger adaptation effects for speech. Thus, in children, individual differences in adaptation reflect constraints imposed by lower-level perceptual differences. In adults, individual differences in adaptation reflect domain- 
general ability to use distributional properties to extract patterned regularities in input and to use these regularities for optimizing task performance.

Although we ensured that all participants included in the study were able to perform the two tasks, the age effects we found could be due to overall worse task performance in children as compared to adults, and not specifically because of perceptual differences. Our findings, therefore, should be interpreted with this caveat in mind. Furthermore, because of the cross-sectional design of our study, age effects could reflect differences between samples, rather than developmental effects. Although the sampling strategies and eligibility criteria were closely matched between the two age samples, future longitudinal studies are needed to replicate the developmental effects we observed.

\section{Conclusion}

The current study investigated the specificity and the causal influences of adaptation deficits in dyslexia in children and adults. We found no support for broad perceptual adaptation deficits in dyslexia or for the causal links between basic processing of acoustic cues or perceptual adaptation to categorical speech perception and subsequently, to phonological awareness. Our study has important implications for understanding the etiological basis of developmental dyslexia. 


\section{References}

Agus, T. R., Carrión-Castillo, A., Pressnitzer, D., \& Ramus, F. (2014). Perceptual Learning of Acoustic Noise by Individuals With Dyslexia. Journal of Speech, Language, and Hearing Research, 57(3), 1069-1077. https://doi.org/10.1044/1092-4388(2013/13-0020)

Ahissar, M. (2007). Dyslexia and the anchoring-deficit hypothesis. Trends in Cognitive Sciences, 11(11), 458-465.

Ahissar, M., Lubin, Y., Putter-Katz, H., \& Banai, K. (2006). Dyslexia and the failure to form a perceptual anchor. Nature Neuroscience, 9(12), 1558-1564. https://doi.org/10.1038/nn1800

Ahissar, M., Protopapas, A., Reid, M., \& Merzenich, M. M. (2000). Auditory processing parallels reading abilities in adults. Proceedings of the National Academy of Sciences, 97(12), 6832-6837.

Allen, J. S., Miller, J. L., \& DeSteno, D. (2003). Individual talker differences in voice-onsettime. The Journal of the Acoustical Society of America, 113(1), 544-552.

Amir, O., Amir, N., \& Kishon-Rabin, L. (2003). The effect of superior auditory skills on vocal accuracy. The Journal of the Acoustical Society of America, 113(2), 1102-1108.

Amitay, S., Ben-Yehudah, G., Banai, K., \& Ahissar, M. (2002). Disabled readers suffer from visual and auditory impairments but not from a specific magnocellular deficit. Brain, 125(10), 2272-2285.

Baart, M., \& Vroomen, J. (2010). Do you see what you are hearing? Cross-modal effects of speech sounds on lipreading. Neuroscience Letters, 471(2), 100-103.

Banai, K., \& Ahissar, M. (2006). Auditory Processing Deficits in Dyslexia: Task or Stimulus Related? Cerebral Cortex, 16(12), 1718-1728. https://doi.org/10.1093/cercor/bhj107

Banai, K., Hornickel, J., Skoe, E., Nicol, T., Zecker, S., \& Kraus, N. (2009). Reading and subcortical auditory function. Cerebral cortex, 19(11), 2699-2707.

Basu, M., Krishnan, A., \& Weber-Fox, C. (2010). Brainstem correlates of temporal auditory processing in children with specific language impairment. Developmental science, 13(1), 77-91.

Bates, D., Sarkar, D., Bates, M. D., \& Matrix, L. (2007). The lme4 package. R Package Version, 2(1), 74.

Ben-Yehudah, G., \& Ahissar, M. (2004). Sequential spatial frequency discrimination is consistently impaired among adult dyslexics. Vision Research, 44(10), 1047-1063. https://doi.org/10.1016/j.visres.2003.12.001

Bishop, D. V. M. (2013). Cerebral Asymmetry and Language Development: Cause, Correlate, or Consequence? Science, 340(6138), 1230531-1230531. https://doi.org/10.1126/science.1230531

Blomert, L., Mitterer, H., \& Paffen, C. (n.d.). In Search of the Auditory, Phonetic, and/or Phonological Problems in Dyslexia: Context Effects in Speech Perception. 18.

Boets, B., Wouters, J., Van Wieringen, A., De Smedt, B., \& Ghesquiere, P. (2008). Modelling relations between sensory processing, speech perception, orthographic and phonological ability, and literacy achievement. Brain and Language, 106(1), 29-40.

Bogliotti, C. (2003, August). Relation between categorical perception of speech and reading acquisition. In Proceedings of the 15th International Congress of Phonetic Sciences (pp. 885-888). International Congress of Phonetic Sciences Barcelona, Spain. 
Brady, S., Shankweiler, D., \& Mann, V. (1983). Speech perception and memory coding in relation to reading ability. Journal of Experimental Child Psychology, 35(2), 345-367.

Braida, L. D., Lim, J. S., Berliner, J. E., Durlach, N. I., Rabinowitz, W. M., \& Purks, S. R. (1984). Intensity perception. XIII. Perceptual anchor model of context-coding. The Journal of the Acoustical Society of America, 76(3), 722-731.

Burnham, D. K., Earnshaw, L. J., \& Clark, J. E. (1991). Development of categorical identification of native and non-native bilabial stops: Infants, children and adults. Journal of Child Language, 18(2), 231-260.

Carey, D., Rosen, S., Krishnan, S., Pearce, M. T., Shepherd, A., Aydelott, J., \& Dick, F. (2015). Generality and specificity in the effects of musical expertise on perception and cognition. Cognition, 137, 81-105.

Chandrasekaran, B., Hornickel, J., Skoe, E., Nicol, T., \& Kraus, N. (2009). Context-dependent encoding in the human auditory brainstem relates to hearing speech in noise: Implications for developmental dyslexia. Neuron, 64(3), 311-319.

Christmann, C. A., Lachmann, T., \& Steinbrink, C. (2015). Evidence for a general auditory processing deficit in developmental dyslexia from a discrimination paradigm using speech versus nonspeech sounds matched in complexity. Journal of Speech, Language, and Hearing Research, 58(1), 107-121.

Clayards, M., Tanenhaus, M. K., Aslin, R. N., \& Jacobs, R. A. (2008). Perception of speech reflects optimal use of probabilistic speech cues. Cognition, 108(3), 804-809.

Dunn, D. M. (2018). Peabody picture vocabulary test, 5th Ed. Minneapolis, MN: Pearson Assessments.

Eimas, P. D., \& Corbit, J. D. (1973). Selective adaptation of linguistic feature detectors. Cognitive Psychology, 4(1), 99-109. https://doi.org/10.1016/0010-0285(73)90006-6

Eimas, P. D., Siqueland, E. R., Jusczyk, P., \& Vigorito, J. (1971). Speech Perception in Infants. Science, 171(3968), 303-306. https://doi.org/10.1126/science.171.3968.303

Eisner, F., \& McQueen, J. M. (2005). The specificity of perceptual learning in speech processing. Perception \& psychophysics, 67(2), 224-238

Eisner, F., \& McQueen, J. M. (2006). Perceptual learning in speech: Stability over time. The Journal of the Acoustical Society of America, 119(4), 1950-1953.

Feldman, N. H., Griffiths, T. L., \& Morgan, J. L. (2009). The influence of categories on perception: Explaining the perceptual magnet effect as optimal statistical inference. Psychological Review, 116(4), 752.

Gaab, N., Tallal, P., Kim, H., Lakshminarayanan, K., Archie, J. J., Glover, G. H., \& Gabrieli, J. D. E. (2005). Neural correlates of rapid spectrotemporal processing in musicians and nonmusicians. Annals of the New York Academy of Sciences, 1060(1), 82-88.

Gabay, Y., \& Holt, L. L. (2015). Incidental learning of sound categories is impaired in developmental dyslexia. Cortex, 73, 131-143.

Gabay, Y., \& Holt, L. L. (2018). Short-term adaptation to sound statistics is unimpaired in developmental dyslexia. PLOS ONE, 13(6), e0198146. https://doi.org/10.1371/journal.pone.0198146

Gabay, Y., \& Holt, L. L. (2021). Adaptive Plasticity Under Adverse Listening Conditions is Disrupted in Developmental Dyslexia. Journal of the International Neuropsychological Society, 27(1), 12-22.

Gabay, Y., Najjar, I.-J., \& Reinisch, E. (2019). Another Temporal Processing Deficit in Individuals With Developmental Dyslexia: The Case of Normalization for Speaking 
Rate. Journal of Speech, Language, and Hearing Research, 62(7), 2171-2184. https://doi.org/10.1044/2019_JSLHR-S-18-0264

Gabay, Y., Vakil, E., Schiff, R., \& Holt, L. L. (2015). Probabilistic category learning in developmental dyslexia: Evidence from feedback and paired-associate weather prediction tasks. Neuropsychology, 29(6), 844.

Goswami, U. (2002). Phonology, reading development, and dyslexia: A cross-linguistic perspective. Annals of Dyslexia, 52(1), 139-163.

Goswami, U. (2011). A temporal sampling framework for developmental dyslexia. Trends in Cognitive Sciences, 15(1), 3-10.

Goswami, U., Huss, M., Mead, N., \& Fosker, T. (2020). Auditory Sensory Processing and Phonological Development in High IQ and Exceptional Readers, Typically Developing Readers, and Children With Dyslexia: A Longitudinal Study. Child Development, cdev.13459. https://doi.org/10.1111/cdev.13459

Griffiths, T. D., \& Hall, D. A. (2012). Mapping pitch representation in neural ensembles with fMRI. Journal of Neuroscience, 32(39), 13343-13347.

Grube, M., Cooper, F. E., Kumar, S., Kelly, T., \& Griffiths, T. D. (2014). Exploring the role of auditory analysis in atypical compared to typical language development. Hearing Research, 308, 129-140.

Halliday, L. F., \& Bishop, D. V. M. (2006). Auditory frequency discrimination in children with dyslexia. Journal of Research in Reading, 29(2), 213-228. https://doi.org/10.1111/j.14679817.2006.00286.x

Hämäläinen, J. A., Salminen, H. K., \& Leppänen, P. H. T. (2013). Basic Auditory Processing Deficits in Dyslexia: Systematic Review of the Behavioral and Event-Related Potential/ Field Evidence. Journal of Learning Disabilities, 46(5), 413-427. https://doi.org/10.1177/0022219411436213

Harrell Jr, F. E., \& Harrell Jr, M. F. E. (2019). Package 'hmisc.' CRAN2018, 2019, 235-236.

Hayes, A. F. (2012). PROCESS: A versatile computational tool for observed variable mediation, moderation, and conditional process modeling. University of Kansas, KS.

Hazan, V., \& Barrett, S. (2000). The development of phonemic categorization in children aged 6-12. Journal of Phonetics, 28(4), 377-396.

Ho, J., Tumkaya, T., Aryal, S., Choi, H., \& Claridge-Chang, A. (2019). Moving beyond P values: Data analysis with estimation graphics. Nature Methods, 16(7), 565-566.

Hoonhorst, I., Medina, V., Colin, C., Markessis, E., Radeau, M., Deltenre, P., \& Serniclaes, W. (2011). Categorical perception of voicing, colors and facial expressions: A developmental study. Speech Communication, 53(3), 417-430.

Hornickel, J., \& Kraus, N. (2013). Unstable representation of sound: A biological marker of dyslexia. Journal of Neuroscience, 33(8), 3500-3504.

Hornickel, J., Chandrasekaran, B., Zecker, S., \& Kraus, N. (2011). Auditory brainstem measures predict reading and speech-in-noise perception in school-aged children. Behavioural brain research, 216(2), 597-605.

Idemaru, K., \& Holt, L. L. (2011). Word recognition reflects dimension-based statistical learning. Journal of Experimental Psychology: Human Perception and Performance, 37(6), 1939.

Jaeger, T. F. (2008). Categorical data analysis: Away from ANOVAs (transformation or not) and towards logit mixed models. Journal of Memory and Language, 59(4), 434-446.

Jeffreys, H. (1998). The theory of probability. OUP Oxford. 
Jensen, J. K., \& Neff, D. L. (1993). Development of basic auditory discrimination in preschool children. Psychological Science, 4(2), 104-107.

Kaufman, A. S. (2004). Kaufman brief intelligence test-second edition (KBIT-2). Circle Pines, $\mathrm{MN}$ : American Guidance Service.

Killion, M. C., Niquette, P. A., Gudmundsen, G. I., Revit, L. J., \& Banerjee, S. (2004). Development of a quick speech-in-noise test for measuring signal-to-noise ratio loss in normal-hearing and hearing-impaired listeners. The Journal of the Acoustical Society of America, 116(4), 2395-2405.

Kleinschmidt, D. F., \& Jaeger, T. F. (2015). Robust speech perception: Recognize the familiar, generalize to the similar, and adapt to the novel. Psychological Review, 122(2), 148-203. https://doi.org/10.1037/a0038695

Koelsch, S., Schröger, E., \& Tervaniemi, M. (1999). Superior pre-attentive auditory processing in musicians. Neuroreport, 10(6), 1309-1313.

Kraljic, T., \& Samuel, A. G. (2006). Generalization in perceptual learning for speech. Psychonomic bulletin \& review, 13(2), 262-268.

Kronrod, Y., Coppess, E., \& Feldman, N. (2012). A unified model of categorical effects in consonant and vowel perception. 34(34).

Kuznetsova, A., Brockhoff, P. B., \& Christensen, R. H. B. (2016). Tests in linear mixed effects models. R Package Version, 2, 33.

Lee, S.-Y., \& Song, X.-Y. (2004). Evaluation of the Bayesian and maximum likelihood approaches in analyzing structural equation models with small sample sizes. Multivariate Behavioral Research, 39(4), 653-686.

Liu, W., Shu, H., \& Yang, Y. (2009). Speech perception deficits by Chinese children with phonological dyslexia. Journal of Experimental Child Psychology, 103(3), 338-354. https://doi.org/10.1016/j.jecp.2009.03.005

Lorusso, M. L., Cantiani, C., \& Molteni, M. (2014). Age, dyslexia subtype and comorbidity modulate rapid auditory processing in developmental dyslexia. Frontiers in Human Neuroscience, 8, 313.

Luke, S. G. (2017). Evaluating significance in linear mixed-effects models in R. Behavior Research Methods, 49(4), 1494-1502.

Lum, J. A. G., Ullman, M. T., \& Conti-Ramsden, G. (2013). Procedural learning is impaired in dyslexia: Evidence from a meta-analysis of serial reaction time studies. Research in Developmental Disabilities, 34(10), 3460-3476. https://doi.org/10.1016/j.ridd.2013.07.017

Magne, C., Schön, D., \& Besson, M. (2006). Musician children detect pitch violations in both music and language better than nonmusician children: Behavioral and electrophysiological approaches. Journal of Cognitive Neuroscience, 18(2), 199-211.

Manis, F. R., McBride-Chang, C., Seidenberg, M. S., Keating, P., Doi, L. M., Munson, B., \& Petersen, A. (1997). Are speech perception deficits associated with developmental dyslexia? Journal of Experimental Child Psychology, 66(2), 211-235.

Marshall C. M., Snowling Margaret J., \& Bailey Peter J. (2001). Rapid Auditory Processing and Phonological Ability in Normal Readers and Readers With Dyslexia. Journal of Speech, Language, and Hearing Research, 44(4), 925-940. https://doi.org/10.1044/10924388(2001/073)

Maxon, A. B., \& Hochberg, I. (1982). Development of psychoacoustic behavior: Sensitivity and discrimination. Ear and Hearing, 3(6), 301-308. 
McMurray, B., Danelz, A., Rigler, H., \& Seedorff, M. (2018). Speech categorization develops slowly through adolescence. Developmental Psychology, 54(8), 1472.

Menghini, D., Hagberg, G. E., Petrosini, L., Bozzali, M., Macaluso, E., Caltagirone, C., \& Vicari, S. (2008). Structural Correlates of Implicit Learning Deficits in Subjects with Developmental Dyslexia. Annals of the New York Academy of Sciences, 1145(1), 212221. https://doi.org/10.1196/annals.1416.010

Moreno, S. (2009). Can music influence language and cognition? Contemporary Music Review, 28(3), 329-345.

Morey, R. D., Rouder, J. N., Jamil, T., \& Morey, M. R. D. (2015). Package 'bayesfactor.' URLh Http://Cran/r-Projectorg/Web/Packages/BayesFactor/BayesFactor Pdf i (Accessed 1006 $15)$.

Newman, R. S., Clouse, S. A., \& Burnham, J. L. (2001). The perceptual consequences of withintalker variability in fricative production. The Journal of the Acoustical Society of America, 109(3), 1181-1196.

Nittrouer, S. (1992). Age-related differences in perceptual effects of formant transitions within syllables and across syllable boundaries. Journal of Phonetics, 20(3), 351-382.

Nittrouer, S. (1999). Do temporal processing deficits cause phonological processing problems?. Journal of Speech, Language, and Hearing Research, 42(4), 925-942.

Nittrouer, S. (2002). Learning to perceive speech: How fricative perception changes, and how it stays the same. The Journal of the Acoustical Society of America, 112(2), 711-719.

Nittrouer, S., \& Crowther, C. S. (1998). Examining the role of auditory sensitivity in the developmental weighting shift. Journal of Speech, Language, and Hearing Research, 41(4), 809-818.

Nittrouer, S., \& Miller, M. E. (1997). Developmental weighting shifts for noise components of fricative-vowel syllables. The Journal of the Acoustical Society of America, 102(1), 572580.

Noordenbos, M. W., \& Serniclaes, W. (2015). The Categorical Perception Deficit in Dyslexia: A Meta-Analysis. Scientific Studies of Reading, 19(5), 340-359. https://doi.org/10.1080/10888438.2015.1052455

Oganian, Y., \& Ahissar, M. (2012). Poor anchoring limits dyslexics' perceptual, memory, and reading skills. Neuropsychologia, 50(8), 1895-1905. https://doi.org/10.1016/j.neuropsychologia.2012.04.014

Ozernov-Palchik, O., Yu, X., Wang, Y., \& Gaab, N. (2016). Lessons to be learned: How a comprehensive neurobiological framework of atypical reading development can inform educational practice. Current Opinion in Behavioral Sciences, 10, 45-58.

Panneton, R., \& Newman, R. (2012). Development of Speech Perception. In L. Werner, R. R. Fay, \& A. N. Popper (Eds.), Human Auditory Development (pp. 197-222). Springer. https://doi.org/10.1007/978-1-4614-1421-6_7

Pennington, B. F. (2006). From single to multiple deficit models of developmental disorders. Cognition, 101(2), 385-413. https://doi.org/10.1016/j.cognition.2006.04.008

Perrachione, T. K., Del Tufo, S. N., Winter, R., Murtagh, J., Cyr, A., Chang, P., Halverson, K., Ghosh, S. S., Christodoulou, J. A., \& Gabrieli, J. D. E. (2016). Dysfunction of Rapid Neural Adaptation in Dyslexia. Neuron, 92(6), 1383-1397. https://doi.org/10.1016/j.neuron.2016.11.020 
Peter, B., McCollum, H., Daliri, A., \& Panagiotides, H. (2019). Auditory gating in adults with dyslexia: An ERP account of diminished rapid neural adaptation. Clinical Neurophysiology, 130(11), 2182-2192.

Pierrehumbert, J. B. (2003). Phonetic diversity, statistical learning, and acquisition of phonology. Language and speech, 46(2-3), 115-154.

Poelmans, G., Buitelaar, J. K., Pauls, D., \& Franke, B. (2011). A theoretical molecular network for dyslexia: Integrating available genetic findings. Molecular Psychiatry, 16(4), 365382.

Ramus, F. (2003). Theories of developmental dyslexia: Insights from a multiple case study of dyslexic adults. Brain, 126(4), 841-865. https://doi.org/10.1093/brain/awg076

Rose, J. E., Brugge, J. F., Anderson, D. J., \& Hind, J. E. (1967). Phase-locked response to lowfrequency tones in single auditory nerve fibers of the squirrel monkey. Journal of neurophysiology, 30(4), 769-793.

Rosen, S. (2003). Auditory processing in dyslexia and specific language impairment: Is there a deficit? What is its nature? Does it explain anything? Journal of Phonetics, 31(3-4), 509527. https://doi.org/10.1016/S0095-4470(03)00046-9

Rosseel, Y. (2014). Structural equation modeling with lavaan. Using R for Personality Research, $1-127$.

Saffran, J. R., Aslin, R. N., \& Newport, E. L. (1996). Statistical Learning by 8-Month-Old Infants. Science, 274(5294), 1926-1928. https://doi.org/10.1126/science.274.5294.1926

Samuel, A. G. (1986). Red herring detectors and speech perception: In defense of selective adaptation. Cognitive Psychology, 18(4), 452-499. https://doi.org/10.1016/00100285(86)90007-1

Samuel, A. G., \& Kat, D. (1998). Adaptation is automatic. Perception \& Psychophysics, 60(3), 503-510.

Schneider, P., \& Wengenroth, M. (2009). The neural basis of individual holistic and spectral sound perception. Contemporary Music Review, 28(3), 315-328.

Schön, D., Magne, C., \& Besson, M. (2004). The music of speech: Music training facilitates pitch processing in both music and language. Psychophysiology, 41(3), 341-349.

Shankweiler, D., Liberman, I. Y., Mark, L. S., Fowler, C. A., \& Fischer, F. W. (1979). The speech code and learning to read. Journal of Experimental Psychology: Human Learning and Memory, 5(6), 531.

Slawinski, E. B., \& Fitzgerald, L. K. (1998). Perceptual development of the categorization of the/rw/contrast in normal children. Journal of Phonetics, 26(1), 27-43.

Snowling, M. J. (2000). Dyslexia. Blackwell publishing.

Sperling, A. J., Lu, Z.-L., Manis, F. R., \& Seidenberg, M. S. (2005). Deficits in perceptual noise exclusion in developmental dyslexia. Nature Neuroscience, 8(7), 862-863.

Stanovich, K. E., \& Siegel, L. S. (1994). Phenotypic performance profile of children with reading disabilities: A regression-based test of the phonological-core variable-difference model. Journal of Educational Psychology, 86(1), 24.

Steinbrink, C., Knigge, J., Mannhaupt, G., Sallat, S., \& Werkle, A. (2019). Are Temporal and tonal musical skills related to phonological awareness and literacy skills?-Evidence from two cross-sectional studies with children from different age groups. Frontiers in Psychology, 10, 805.

Stephens, J. D., \& Holt, L. L. (2011). A standard set of American-English voiced stop-consonant stimuli from morphed natural speech. Speech Communication, 53(6), 877-888. 
Stoodley, C. J., Ray, N. J., Jack, A., \& Stein, J. F. (2008). Implicit Learning in Control, Dyslexic, and Garden-Variety Poor Readers. Annals of the New York Academy of Sciences, 1145(1), 173-183. https://doi.org/10.1196/annals.1416.003

Sussman Joan E. (1993). Perception of Formant Transition Cues to Place of Articulation in Children With Language Impairments. Journal of Speech, Language, and Hearing Research, 36(6), 1286-1299. https://doi.org/10.1044/jshr.3606.1286

Sussman Joan E. \& Carney Arlene Earley. (1989). Effects of Transition Length on the Perception of Stop Consonants by Children and Adults. Journal of Speech, Language, and Hearing Research, 32(1), 151-160. https://doi.org/10.1044/jshr.3201.151

Tallal, P. (1980). Language and reading: Some perceptual prerequisites. Bulletin of the Orton Society, 30(1), 170-178.

Tallal, P. (1984). Temporal or phonetic processing deficit in dyslexia? That is the question. Applied Psycholinguistics, 5(2), 167-169.

Tallal, P., \& Piercy, M. (1973). Defects of non-verbal auditory perception in children with developmental aphasia. Nature, 241(5390), 468-469.

Tallal, P., Miller, S., \& Fitch, R. H. (1993). Neurobiological basis of speech: A case for the preeminence of temporal processing. ANNALS-NEW YORK ACADEMY OF SCIENCES, 682, 27-27.

Team, R. C. (2013). R: A language and environment for statistical computing. Vienna, Austria.

Thompson, N. C., Cranford, J. L., \& Hoyer, E. (1999). Brief-tone frequency discrimination by children. Journal of Speech, Language, and Hearing Research, 42(5), 1061-1068.

Torgesen, J. K., Wagner, R., \& Rashotte, C. (2012). Test of Word Reading Efficiency:(TOWRE2). Pearson Clinical Assessment.

Vandermosten, M., Boets, B., Luts, H., Poelmans, H., Golestani, N., Wouters, J., \& Ghesquiere, P. (2010). Adults with dyslexia are impaired in categorizing speech and nonspeech sounds on the basis of temporal cues. Proceedings of the National Academy of Sciences, 107(23), 10389-10394. https://doi.org/10.1073/pnas.0912858107

Vandermosten, M., Boets, B., Luts, H., Poelmans, H., Wouters, J., \& Ghesquière, P. (2011). Impairments in speech and nonspeech sound categorization in children with dyslexia are driven by temporal processing difficulties. Research in Developmental Disabilities, 32(2), 593-603. https://doi.org/10.1016/j.ridd.2010.12.015

Vandermosten, M., Correia, J., Vanderauwera, J., Wouters, J., Ghesquière, P., \& Bonte, M. (2020). Brain activity patterns of phonemic representations are atypical in beginning readers with family risk for dyslexia. Developmental Science, 23(1), e12857.

Vanvooren, S., Poelmans, H., De Vos, A., Ghesquière, P., \& Wouters, J. (2017). Do prereaders' auditory processing and speech perception predict later literacy? Research in Developmental Disabilities, 70, 138-151.

Vellutino, F. R., Scanlon, D. M., \& Tanzman, M. S. (1994). Components of reading ability: Issues and problems in operationalizing word identification, phonological coding, and orthographic coding.

Waber, D. P., Weiler, M. D., Wolff, P. H., Bellinger, D., Marcus, D. J., Ariel, R., Forbes, P., \& Wypij, D. (2001). Processing of Rapid Auditory Stimuli in School-Age Children Referred for Evaluation of Learning Disorders. Child Development, 72(1), 37-49. https://doi.org/10.1111/1467-8624.00264

Wagner, R. K., Torgesen, J. K., Rashotte, C. A., \& Pearson, N. A. (1999). Comprehensive test of phonological processing: CTOPP. Pro-ed Austin, TX. 
Walley, A. C., \& Flege, J. E. (1999). Effect of lexical status on children's and adults' perception of native and non-native vowels. Journal of Phonetics, 27(3), 307-332. https://doi.org/10.1006/jpho.1999.0098

West, G., Melby-Lervåg, M., \& Hulme, C. (2021). Is a procedural learning deficit a causal risk factor for developmental language disorder or dyslexia? A meta-analytic review. Developmental Psychology, 57(5), 749.

Wetzels, R., Matzke, D., Lee, M. D., Rouder, J. N., Iverson, G. J., \& Wagenmakers, E.-J. (2011). Statistical evidence in experimental psychology: An empirical comparison using $855 \mathrm{t}$ tests. Perspectives on Psychological Science, 6(3), 291-298.

Wiederholt, J. L., Bryant, B. R., \& Gray, W. S. (2001). Gray oral reading tests: Examiner's manual. Pro-Ed.

Wier, C. C., Jesteadt, W., \& Green, D. M. (1977). Frequency discrimination as a function of frequency and sensation level. The Journal of the Acoustical Society of America, 61(1), $178-184$.

Wijnen, F., Kappers, A. M. L., Vlutters, L. D., \& Winkel, S. (2012). Auditory Frequency Discrimination in Adults With Dyslexia: A Test of the Anchoring Hypothesis. Journal of Speech, Language, and Hearing Research, 55(5), 1387-1394. https://doi.org/10.1044/1092-4388(2012/10-0302)

Witton, C., Swoboda, K., Shapiro, L. R., \& Talcott, J. B. (2020). Auditory frequency discrimination in developmental dyslexia: A meta-analysis. Dyslexia, 26(1), 36-51.

Wolf, M., \& Denckla, M. B. (2005). The rapid automatized naming and rapid alternating stimulus tests (RAN/RAS). Pro-ed.

Woodcock, R. W. (2011). Woodcock reading mastery tests: WRMT-III. Pearson.

Wright, C., Conlon, E., Wright, M., \& Dyck, M. (2011). Sub-lexical reading intervention in a student with dyslexia and Asperger's Disorder. Australian Journal of Educational \& Developmental Psychology, 11, 11-25.

Ziegler, J. C., Pech-Georgel, C., George, F., \& Lorenzi, C. (2009). Speech-perception-in-noise deficits in dyslexia. Developmental Science, 12(5), 732-745.

Zuk, J., Bishop-Liebler, P., Ozernov-Palchik, O., Moore, E., Overy, K., Welch, G., \& Gaab, N. (2017). Revisiting the "enigma" of musicians with dyslexia: Auditory sequencing and speech abilities. Journal of Experimental Psychology: General, 146(4), 495.

Zuk, J., Ozernov-Palchik, O., Kim, H., Lakshminarayanan, K., Gabrieli, J. D. E., Tallal, P., \& Gaab, N. (2013). Enhanced Syllable Discrimination Thresholds in Musicians. PLOS ONE, 8(12), e80546. https://doi.org/10.1371/journal.pone.0080546 
Supplemental Table 1: Correlations among perceptual variables by group. Pairwise

correlation for children (grey) and adults (striped) between Phonological Awareness (PA), the selective adaptation effect (Adaptation), the speech identification slope (Slope), the tone frequency discrimination threshold (JND), and the anchoring effect (NTD). Correlation coefficients are Spearman rho.

Typical

\begin{tabular}{|c|c|c|c|c|c|}
\hline & $\begin{array}{c}\text { Tone } \\
\text { discrimination }\end{array}$ & $\begin{array}{c}\text { Tone } \\
\text { anchoring }\end{array}$ & $\begin{array}{l}\text { Categorical } \\
\text { perception }\end{array}$ & $\begin{array}{c}\text { Speech } \\
\text { adaptation }\end{array}$ & $\begin{array}{c}\text { Phonological } \\
\text { awareness }\end{array}$ \\
\hline $\begin{array}{c}\text { Tone } \\
\text { discrimination }\end{array}$ & 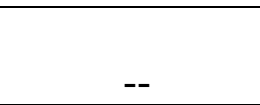 & $\begin{array}{c}-0.53^{*} \\
(\mathrm{BF}=10.16)\end{array}$ & $\begin{array}{c}-0.10 \\
(\mathrm{BF}=0.41)\end{array}$ & $\begin{array}{c}-0.02 \\
(\mathrm{BF}=0.51)\end{array}$ & $\begin{array}{c}-0.19 \\
(\mathrm{BF}=2.39)\end{array}$ \\
\hline Tone anchoring & $\begin{array}{c}-0.38 \\
(\mathrm{BF}=3.25)\end{array}$ & -- & $\begin{array}{c}0.04 \\
(\mathrm{BF}=0.4)\end{array}$ & $\begin{array}{c}0.07 \\
(\mathrm{BF}=0.41)\end{array}$ & $\begin{array}{c}0.16 \\
(\mathrm{BF}=0.73)\end{array}$ \\
\hline $\begin{array}{l}\text { Categorical } \\
\text { perception }\end{array}$ & $\begin{array}{c}-0.17 \\
(\mathrm{BF}=0.56)\end{array}$ & $\begin{array}{c}0.05 \\
(\mathrm{BF}=0.5)\end{array}$ & -- & $\begin{array}{c}0.39^{*} \\
(\mathrm{BF}=5.91)\end{array}$ & $\begin{array}{c}-0.05 \\
(\mathrm{BF}=0.41)\end{array}$ \\
\hline $\begin{array}{c}\text { Speech } \\
\text { adaptation }\end{array}$ & $\begin{array}{c}0.08 \\
(\mathrm{BF}=0.46)\end{array}$ & $\begin{array}{c}0.32 \\
(\mathrm{BF}=1.13)\end{array}$ & $\begin{array}{c}0.10 \\
(\mathrm{BF}=0.59)\end{array}$ & 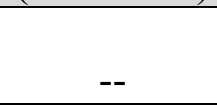 & $\begin{array}{c}-0.39^{*} \\
(\mathrm{BF}=1.39)\end{array}$ \\
\hline $\begin{array}{c}\text { Phonological } \\
\text { awareness }\end{array}$ & $\begin{array}{c}-0.41 \\
(\mathrm{BF}=1.21)\end{array}$ & $\begin{array}{c}0.21 \\
(\mathrm{BF}=0.63)\end{array}$ & $\begin{array}{c}-0.05 \\
(\mathrm{BF}=0.46)\end{array}$ & $\begin{array}{c}-0.07 \\
(\mathrm{BF}=0.46)\end{array}$ & -- \\
\hline
\end{tabular}

\section{Dyslexia}

\begin{tabular}{|c|c|c|c|c|c|}
\hline & $\begin{array}{c}\text { Tone } \\
\text { discrimination } \\
\end{array}$ & Tone anchoring & $\begin{array}{l}\text { Categorical } \\
\text { perception }\end{array}$ & $\begin{array}{c}\text { Speech } \\
\text { adaptation }\end{array}$ & $\begin{array}{c}\text { Phonological } \\
\text { awareness }\end{array}$ \\
\hline $\begin{array}{c}\text { Tone } \\
\text { discrimination }\end{array}$ & 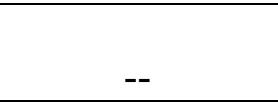 & $\begin{array}{c}-0.21 \\
(\mathrm{BF}=0.92)\end{array}$ & $\begin{array}{c}-0.61 * * \\
(\mathrm{BF}=5.88)\end{array}$ & $\begin{array}{c}-0.20 \\
(\mathrm{BF}=0.63)\end{array}$ & $\begin{array}{c}-0.01 \\
(\mathrm{BF}=0.51)\end{array}$ \\
\hline Tone anchoring & $\begin{array}{c}-0.69^{* *} \\
(\mathrm{BF}=9.05)\end{array}$ & -- & $\begin{array}{c}-0.13 \\
(\mathrm{BF}=0.51)\end{array}$ & $\begin{array}{c}0.14 \\
(\mathrm{BF}=0.62)\end{array}$ & $\begin{array}{c}0.14 \\
(\mathrm{BF}=0.69)\end{array}$ \\
\hline $\begin{array}{l}\text { Categorical } \\
\text { perception }\end{array}$ & $\begin{array}{c}-0.12 \\
(\mathrm{BF}=0.52)\end{array}$ & $\begin{array}{c}-0.12 \\
(\mathrm{BF}=0.58)\end{array}$ & -- & $\begin{array}{c}0.23 \\
(\mathrm{BF}=0.59)\end{array}$ & $\begin{array}{c}0.09 \\
(\mathrm{BF}=0.5)\end{array}$ \\
\hline Speech adaptation & $\begin{array}{c}0.17 \\
(\mathrm{BF}=0.48)\end{array}$ & $\begin{array}{c}-0.09 \\
(\mathrm{BF}=0.47)\end{array}$ & $\begin{array}{c}0.17 \\
(\mathrm{BF}=1.49)\end{array}$ & -- & $\begin{array}{c}0.55^{*} \\
(\mathrm{BF}=1.34)\end{array}$ \\
\hline $\begin{array}{c}\text { Phonological } \\
\text { awareness }\end{array}$ & $\begin{array}{c}-0.17 \\
(\mathrm{BF}=1.03)\end{array}$ & $\begin{array}{c}0.02 \\
(\mathrm{BF}=0.48)\end{array}$ & $\begin{array}{c}0.60^{* *} \\
(\mathrm{BF}=4.64)\end{array}$ & $\begin{array}{c}0.30 \\
(\mathrm{BF}=4.77)\end{array}$ & -- \\
\hline
\end{tabular}




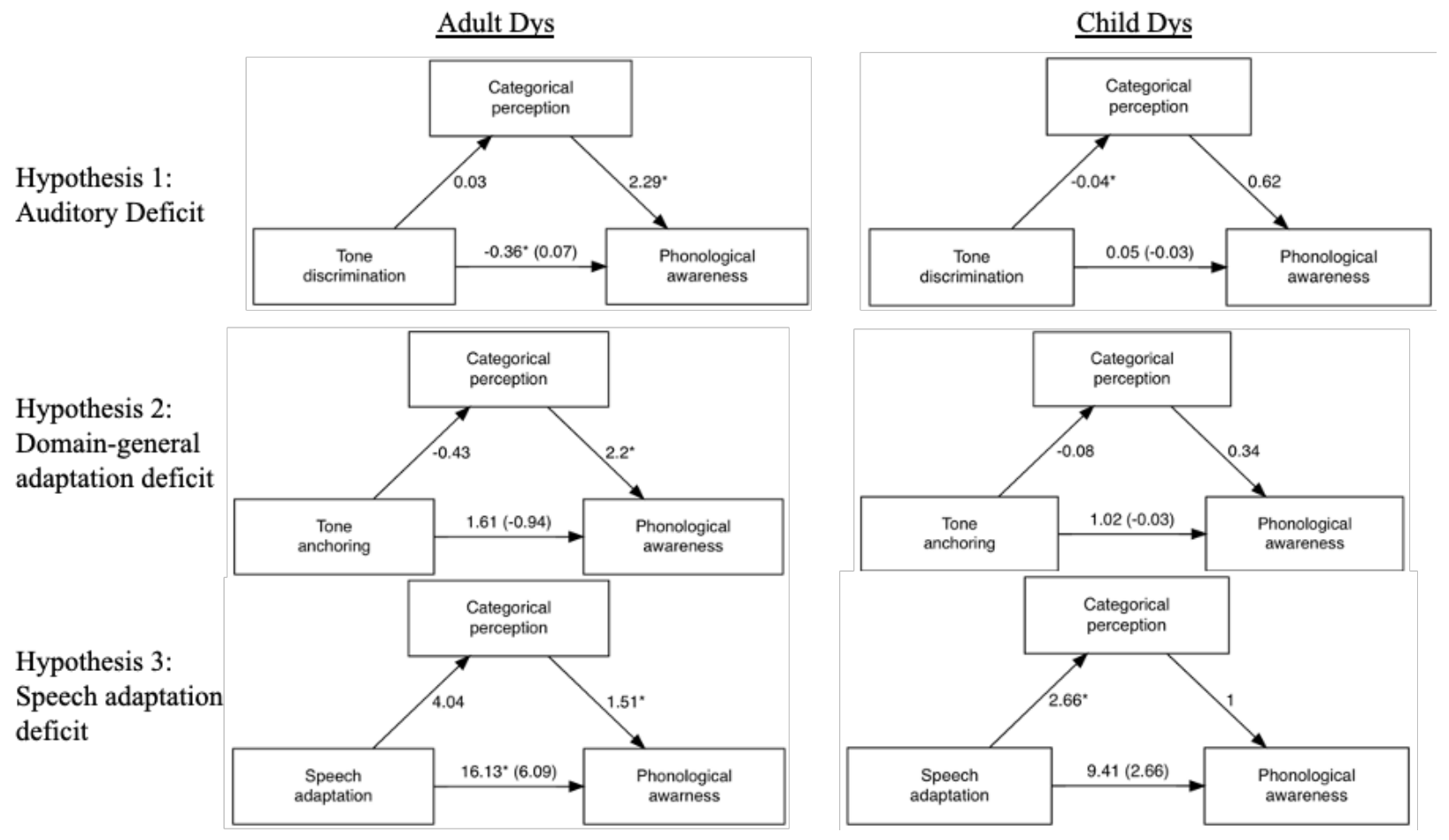

Supplemental Figure 1: Mediation models by age group testing the three hypotheses of causal effects in explaining phonological deficits in dyslexia. Note: ${ }^{*} \mathrm{p}<.05, \uparrow=0.058$.

Supplemental Methods: Participant characteristics by task.

The tone anchoring task was completed by 47 Adults $(N=25$ with dyslexia, 14 female; $N=22$ typical readers, 12 female; age $18-45$ years, $M=27.02, S D=6.9)$ and 50 children $(N=20$ with dyslexia, 10 female; $N=30$ typical readers, 15 female; age $7-10$ years, $M=7.61, S D=0.88$ ). The selective adaptation task was completed by 55 Adults $(N=26$ with dyslexia, 16 female; $N=$ 29 typical readers, 14 female; age $18-45$ years, $M=27.02, S D=6.9)$ and 57 children $(N=26$ with dyslexia, 14 female; $N=31$ typical readers, 15 female; age 7-10 years, $M=7.61, S D=$ $0.88)$. 